\title{
A Novel Solar Powered Milk Cooling Refrigeration Unit with Cold Thermal Energy Storage for Rural Application
}

\section{Shaji Sidney}

Saveetha University Saveetha Engineering College

\section{Rajendran Prabakaran}

Yeungnam University

\section{Sung Chul Kim}

Yeungnam University

Mohan Lal Dhasan ( $\nabla$ dr.mohanlal29@gmail.com )

Anna University Chennai https://orcid.org/0000-0001-7882-3734

\section{Research Article}

Keywords: Solar energy, milk chiller, thermal energy storage, DC compressor, HC-600a, HFC-134a

Posted Date: August 6th, 2021

DOI: https://doi.org/10.21203/rs.3.rs-680630/v1

License: (1) This work is licensed under a Creative Commons Attribution 4.0 International License. Read Full License

Version of Record: A version of this preprint was published at Environmental Science and Pollution Research on October 14th, 2021. See the published version at https://doi.org/10.1007/s11356-02116852-5. 


\title{
A Novel Solar Powered Milk Cooling Refrigeration Unit with Cold Thermal Energy Storage for Rural Application
}

\author{
Shaji Sidney ${ }^{\mathrm{a}}$, Rajendran Prabakaran ${ }^{\mathrm{b}}$, Sung Chul Kim ${ }^{\mathrm{b}}$ and Mohan Lal Dhasan ${ }^{\mathrm{c} *}$ \\ ${ }^{a}$ Department of Energy and Environmental Engineering, Saveetha School of Engineering, Saveetha nagar, Thandalam - Perambakkam - \\ Thakkolam Rd, Tamil Nadu 602 105, India \\ ${ }^{b}$ School of Mechanical Engineering, Yeungnam University, 280 Daehak-Ro, Gyeongsan, Gyeongbuk 712 749, Republic of Korea \\ ${ }^{c}$ Refrigeration and Air Conditioning Division, Department of Mechanical Engineering, College of Engineering Guindy, Anna University, \\ Chennai 600 025, India \\ *Corresponding author: dr.mohanlal29@gmail.com (ML Dhasan)
}

\begin{abstract}
This experimental study analyzed the use of solar photovoltaic energy for operating a novel twin-circuit DC milk chiller without batteries using water-based cold thermal energy storage for different seasons in Chennai, India. HFC-134a and HC-600a were used as refrigerants in the two individual circuits. For each season, the test was conducted continuously for 18 days to analyze the quantity of generated ice that could be utilized to chill 10 L of milk in the morning and in the evening. The average quantity of ice formed per day in the ice bank during monsoon, winter, and summer seasons was found to be 3.61, 19.75, and $27.97 \mathrm{~kg}$, respectively. Thus, it is evident that the use of solar energy with thermal energy storage is effective for operating the milk chilling unit for two seasons, namely winter and summer. However, the system requires an additional power source for continuous operation during the monsoon season. In this study, solar photovoltaic power was observed to be a good choice for chilling milk in the context of global warming and energy consumption. The use of thermal energy storage also allows the initial cost to be reduced.
\end{abstract}

Keywords: Solar energy; milk chiller; thermal energy storage; DC compressor; HC-600a; HFC-134a

\section{Introduction}

The demand for refrigeration for cooling/freezing and food preservation is continuously increasing because of improving living standards and economic development throughout the world (Albayati et al. 2020). The refrigeration sector requires a significant amount of conventional electrical energy, which indirectly results in global warming and $\mathrm{CO} 2$ emissions. According to the International Institute of Refrigeration, approximately 1.5 billion domestic refrigerators and freezers are used globally (Coulomb et al. 2015), and each system requires approximately $450 \mathrm{kWh}$ of power annually (Barthel and Gotz 2012). Globally, this results in annual greenhouse gas emissions of more than 480 million tons of CO2-eq, which is $4 \%$ of the global electricity demand (Coulomb et al. 2015). In the dairy industry, refrigeration plays a vital role in reducing loses related to milk spoilage and also aids in improving the quality of milk, thereby allowing an access to new markets and services. As the initial cost can be high, small to medium sized vapor compression refrigeration (VCR) systems play an important role in cost-effective refrigeration. In the dairy industry, the use of VCR system is very important for cooling raw milk to $4-5{ }^{\circ} \mathrm{C}$ within 2-3 hours to control its microbial count and maintain its quality (FAO and WHO 2011) Many developing countries are exploring realistic solutions to store and preserve milk for 24 hours (Ndyabawe and Kisaalita 2014). The need for electric power operated milk cooling in rural area is also increasing tremendously; though it had huge (around 22.4\%) transmission and transportation losses (Ghafoor and Munir 
2015). Recently, solar refrigeration systems have received significant attention as they can reduce the usage of conventional VCR systems and it can completely eliminate electrical losses from conventional grid supply (Kamalapur and Udaykumar 2011). Solar refrigeration can be of two types: (i) solar photovoltaic (PV) and (ii) solar thermal. The solar thermal systems require a higher investment than the solar PV systems, but can be a better option for high-capacity systems, such as vapor absorption and adsorption refrigeration systems (Selvaraj and Victor 2020; Mostafa et al. 2021) Most recently, Devarajan et al. (2021) used solar thermal system for operating small ejector based refrigeration unit.

The main problem with solar PV systems is that they require a battery bank and direct current (DC) to alternating current (AC) converters to operate existing VCR systems. This increases operational and running costs and reduces the energy conversion efficiency (Gao et al. 2021). Kattakayam and Srinivasan (2000) found that the use of solar PV instead of conventional power increased the AC compressor's operating temperature, which could reduce its life. Opoku et al. (2016) investigated the performance of a VCR system with AC and DC compressors and found similar variations in the cabin and cooling coil temperatures. However, the DC compressor's power consumption was found to be $170-350 \mathrm{~W}$ lower than that of the AC compressor. Thus, DC compressors consume less power and eliminate the need for DC-AC converters. Previous studies have also recommended the use of DC compressors for solar PV refrigeration systems (Torres-Toledo et al. 2016; Sidney and Mohan 2016; Daffallaha 2018; Li et al. 2021)

A major drawback of solar PV systems is the frequent failure of batteries used to store energy. The experimental results of Fezai et al. (2021) elucidated that the battery bank of these systems plays a major role in their reliability and life cycle cost. Batteries can be replaced with thermal energy storage (Driemeier and Zilles 2010) and it can also provide a proper balance between energy required and energy availability (Sharma et al. 2020). Axaopoulos and Theodoridis (2009) developed the first solar PV-based VCR system without batteries for ice generation. They found that the system could run efficiently even with a low solar insolation with four compressors connected in parallel. The experimental results showed that the system could produce 4.5 and 17 $\mathrm{kg}$ of ice per day at a solar insolation of 3 and $7.3 \mathrm{kWh} \cdot \mathrm{m}^{-2}$, respectively. El-Bahloul et al. (2015) experimentally studied the performance of a solar PV driven refrigerator $(50 \mathrm{~L})$ operating with a DC compressor and HFC-134a refrigerant. Experiments were conducted to analyze the effects of thermal energy storage (TES) inclusion in the system. The inclusion of TES resulted in a higher coefficient of performance (COP) than that of a system without TES, and the temperature of the refrigerating cabin could be maintained with low thermal losses during overcast conditions. Kabeel et al. (2018) observed that the power consumption of an airconditioning system was significantly reduced with TES.

De Blas et al. (2003) fabricated a $150 \mathrm{~L}$ milk chiller with two 24 V DC motors, which were directly coupled to separate compressors. The PV energy obtained during sunshine hours was stored in the form of sensible and latent heat of frozen water $(450 \mathrm{~L})$ in a tank surrounding a cylindrical milk tank. Only $80 \%$ of the water underwent a phase change and was able to support the system for 2.5 consecutive cloudy days by maintaining the milk temperature at $4{ }^{\circ} \mathrm{C}$. In this study, the compressors were powered using a fixed DC power source and not directly with a PV source. Hence, the effects of varied solar insolation could not be reviewed. Torres-Toledo et al. (2015) developed a system to rapidly cool $17 \mathrm{~L}$ of milk in a $20 \mathrm{~L}$ milk can using $3 \mathrm{~kg}$ of ice. Two DC compressor refrigerators were used, one operating at $-10^{\circ} \mathrm{C}$ to produce $6 \mathrm{~kg}$ of ice and the other at $4{ }^{\circ} \mathrm{C}$ to preserve $17 \mathrm{~L}$ of milk. Both compressors were operated at $12 \mathrm{~V}$. Water was used as a substitute for milk. The 
use of ice rapidly cooled the milk from 33 to $15^{\circ} \mathrm{C}$, which aided in reducing the risk of spoilage. Sidney et al. (2020) used DC compressors to store cool thermal energy in a $14 \mathrm{~L}$ ice bank tank (IBT) to chill $20 \mathrm{~L}$ of milk. Breen et al. (2020) elucidated that the use of batteries for small PV systems in dairy farms could be avoided by using TES.

Based on previous studies, using a DC compressor and including TES may be a good option when using solar PV power for operating VCR-based milk chillers. Moreover, studies on twin-circuit VCR systems operated with DC compressors and water TES solar PV power are limited. In this study, we examined the feasibility of a solar PV powered twin-circuit (one with HFC-134a and another with HC-600a) DC compressor milk chiller with water-based TES under different climatic conditions. This study can pave the way for using solar energy to run VCR systems in rural areas of India and can help reduce greenhouse gas (GHG) emissions.

\section{Nomenclature}

$\dot{\mathrm{m}}_{\mathrm{r}} \quad$ Refrigerant mass flow rate $\left(\mathrm{kg} \mathrm{s}^{-1}\right)$

AC Alternating Current

$\mathrm{CO}_{2}$-eq Carbon dioxide equivalent

COP Coefficient of Performance

DC Direct Current

evap Evaporator

GHGs Green House Gases

h Specific enthalpy $\left(\mathrm{kJ} \mathrm{Kg}^{-1}\right)$

HC Hydrocarbon

HFC Hydrofluorocarbon

I Current

IBT Ice Bank Tank

PCM Phase Change Material

PUF Polyurethane Form

PV Photo Voltaic

Q Heat Transfer $(\mathrm{kW})$

r Refrigerant

rpm Rotations per minute

RTD Resistance Temperature Detector

TES Thermal Energy Storage

V Voltage

VCR Vapor Compression Refrigeration

$\mathrm{W}_{\text {ele }} \quad$ Electrical power used by the compressor $(\mathrm{kW})$

$\mathrm{W}_{\text {Fan }} \quad$ Electrical power used by the condenser fan $(\mathrm{kW})$

$\mathrm{W}_{\mathrm{p}} \quad$ Peak Wattage 


\section{Experimental facilities}

\section{Test setup}

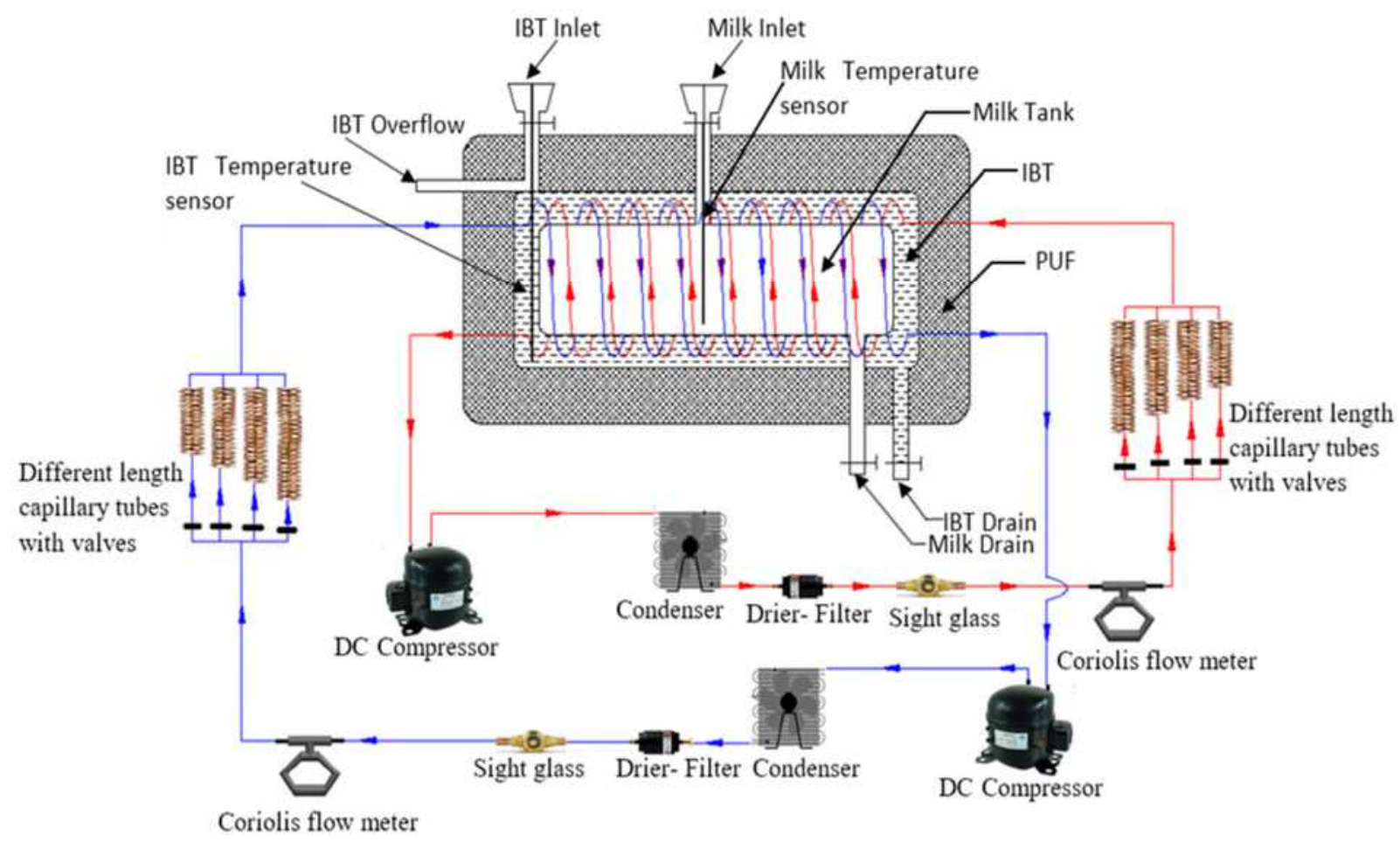

Fig. 1. Schematic representation of the experimental setup

A schematic representation of the customized milk chiller with a milk tank and an IBT for TES is shown in Fig. 1. The milk tank was made of food-grade standard stainless steel with a storage capacity of $20 \mathrm{~L}$, and encapsulated in a 40 L IBT made of food-grade standard stainless steel with copper evaporator tubes wound over the milk tank. The IBT served as a TES to store solar energy. Two evaporator tubes were used, each with a length of $14 \mathrm{~m}$ and diameter of $9.525 \mathrm{~mm}$. The use of the IBT helped minimize the requirement for battery backup during overcast and nocturnal hours. The entire unit was insulated with $100 \mathrm{~mm}$ polyurethane foam (PUF). The milk chiller had two separate refrigerant circuits with individual compressors, condensers, evaporators, and capillary tubes with the same dimensions that were made of the same material. Forced convection air-cooled condensers with a condenser tube diameter of $9.525 \mathrm{~mm}$ and 10 fins per inch were used for both circuits. In the liquid line, two separate drier filters were used to filter the contaminants. Sight glasses were used to visually confirm the refrigerant flow in the liquid line to confirm undercharging conditions and the absence of any impediment. Both circuits were operated with capillary tubes with a length of $4.57 \mathrm{~m}$ and diameter of $0.7874 \mathrm{~mm}$. These dimensions were based on prior capillary tube optimization using the system of Sidney et al. (2020) and the required refrigerant charge was also optimised (Shaji et al. 2021). The IBT and milk tanks had inlet and outlet openings at the top and bottom, respectively. The commencement of freezing was monitored by the discharge of water through the IBT overflow tube. A photograph of the horizontal milk chiller is shown in Fig. 2. 


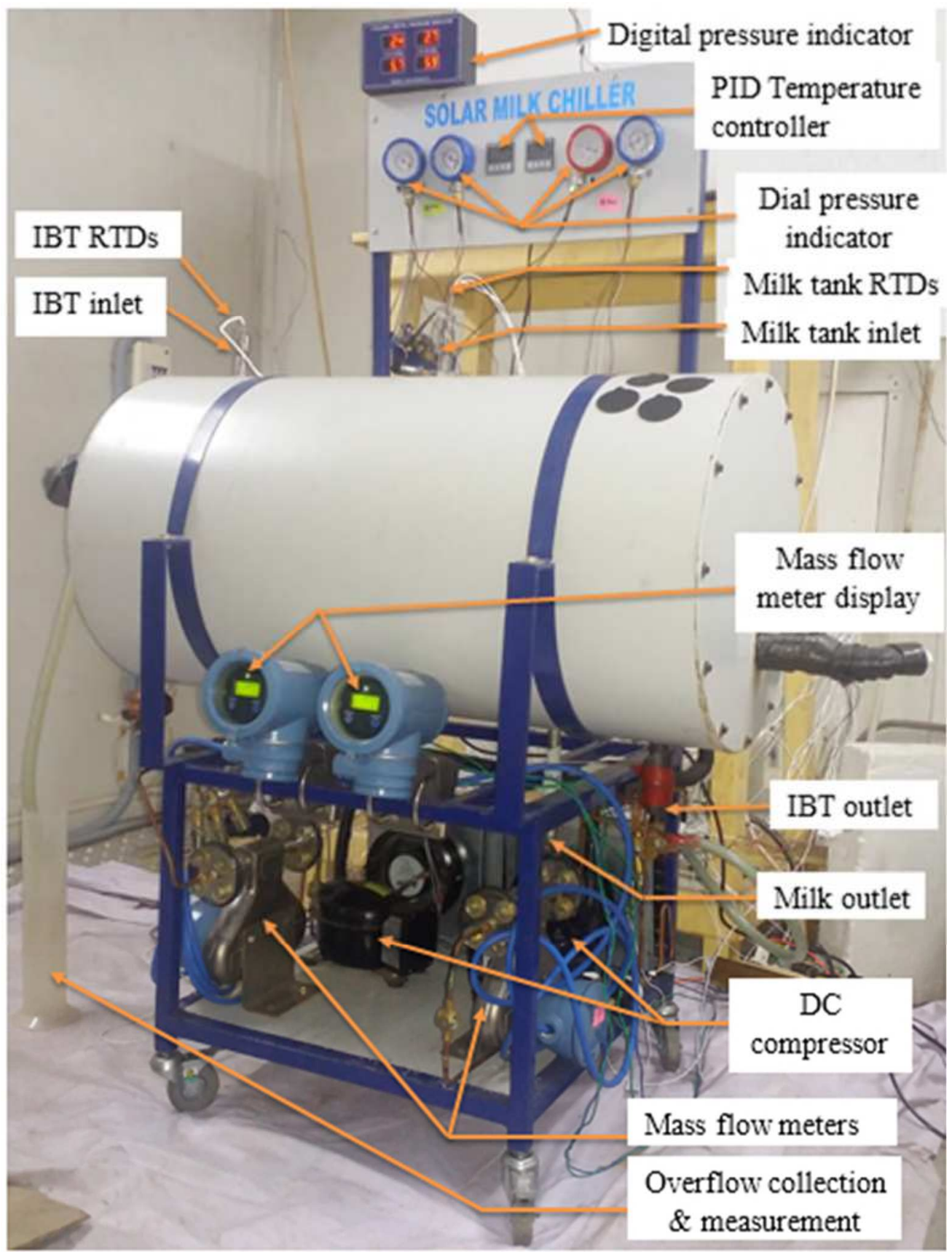

Fig. 2. Photograph of the horizontal milk chiller

Variable-speed DC compressors were used in the milk chiller. The use of variable-speed compressors permitted the system to start cooling early in the morning and late in the afternoon to better utilize the variable solar energy. Furthermore, the use of two compressors enabled the operation of at least one compressor during low solar insolation and operation with two compressors during reasonably good solar insolation. The HC-600a compressor performs better at both low and high solar insolation than the HFC-134a compressor. The cooling effect is higher in the HFC-134a circuit, which is more dominant when the insolation is high. This combination of compressors aids the milk chiller's functionality under certain conditions. These variable-speed compressors have an electronic control circuit that starts the compressor within a time interval of 1 min when powered under a low solar insolation. When the compressor was powered, the initial speed was 2,500 rpm. However, when the 
150 PV panels did not deliver sufficient power, the compressor stopped, and tried to start again by reducing the speed to $400 \mathrm{rpm}$ after a $1 \mathrm{~min}$ interval. If the start failed again, the compressor tried to restart after another minute with a minimum speed of $200 \mathrm{rpm}$. Once the power from the solar panels was sufficient, the compressor started at a low speed, which increased at a rate of $12.5 \mathrm{rpm}$ (Danfoss 2009). Based on the load requirement, two polycrystalline PV panels (Warree), with a capacity of $150 \mathrm{~W}$, were connected in parallel. The specifications of the PV panels are listed in Table 1.

Table 1. Specifications of the installed PV module.

\begin{tabular}{ll}
\hline Model & WS-150/24V \\
\hline Nominal Maximum Power, $\mathrm{P}_{\mathrm{m}}(\mathrm{W})$ & 150 \\
Open circuit voltage, $\mathrm{V}_{\mathrm{oc}}(\mathrm{V})$ & 44.3 \\
Short circuit current, $\mathrm{I}_{\mathrm{sc}}(\mathrm{A})$ & 4.51 \\
Voltage at maximum power, $\mathrm{V}_{\mathrm{mp}}(\mathrm{V})$ & 35.85 \\
Current at maximum power, $\mathrm{I}_{\mathrm{mp}}(\mathrm{A})$ & 4.19 \\
Module Efficiency $(\%)$ & $14.91 \%$ \\
Length $\mathrm{X}$ Width $\mathrm{x}$ Thickness $(\mathrm{mm})$ & $1490 \times 675 \times 35$ \\
Weight $(\mathrm{kg})$ & 13 \\
Cells Per module (units)/Arrangement & $72 /(12 \times 6)$ \\
Cell type & Polycrystalline \\
& Silicon \\
Front cover (Material/Thickness) & Tempered \& Low \\
& Iron Glass, 3.2/4.0 \\
Temperature Coefficient of & mm \\
Current $/{ }^{\circ} \mathrm{C}$ & 0.0051 \\
Temperature Coefficient of & -0.2775 \\
Voltage $/{ }^{\circ} \mathrm{C}$ & \\
Temperature Coefficient of Power $/{ }^{\circ} \mathrm{C}$ & -0.3859 \\
\hline
\end{tabular}

The temperatures across all major components of the refrigeration circuits, suction/discharge pressures, refrigerant mass flow rates, temperatures of IBT and milk, current, and voltage were interfaced with a computer via an Agilent data logger. Resistance temperature detectors (RTDs, PT100, $\pm 0.15{ }^{\circ} \mathrm{C}$ ) were used to measure the temperatures. The suction/discharge pressures were measured using pressure transmitters (MEAS - M5156, $\pm 5 \%$ ). The refrigerant mass flow rates were measured along the liquid line using Micro Motion ELITE Coriolistype mass flow meters (Micro Motion ELITE, $\pm 0.15 \%$ ). An ammeter and a voltmeter were fixed between the solar panels and compressors to measure the power consumed by the compressors. The solar insolation, ambient temperature, and wind speed were measured and logged using a DAVIS-Vantage Pro-2 weather station.

\section{Selection of phase change material (PCM)}

The PCM selection was based on the application type and operating range. For a milk chilling application, the raw milk has to be maintained at approximately $4-5{ }^{\circ} \mathrm{C}$ to control its microbial count. Referring to the required application temperature, water was used as the phase change material (PCM) in the IBT, with a phase change temperature of $0{ }^{\circ} \mathrm{C}$. Water is advantageous because of a high latent heat during phase change, apart from being non-toxic and non-flammable. As the system is used for food storage, the use of water as a PCM is appropriate. 


\section{Experimental procedure}

The experiments were carried out during three different seasons (monsoon, winter, and summer) at Anna University, Chennai $\left(13.0076^{\circ} \mathrm{N}, 80.2397^{\circ} \mathrm{E}\right)$. The field test was carried out by directly connecting the PV panels with the DC compressors without any other charge controller or battery backup. Before commencing the seasonal experiments, the IBT temperature of the milk tank was maintained at $30{ }^{\circ} \mathrm{C}$. The experiments were carried out in a climate chamber maintained at $32{ }^{\circ} \mathrm{C}$ for all three seasonal conditions. The experiments were carried out continuously for 18 days during each season to analyze the operational feasibility of the designed milk chiller without any battery backup. When ice formation started in the IBT, an equivalent volume of water from the IBT was sent off through the overflow tube because of the change in the specific volume of ice. The overflown water was collected and measured, based on which the ice weight was determined. A similar method has been used previously by Xu et al. (2017) and Han et al. (2019).

The experiments used water in the place of milk [21]. Two milking phases were considered in the study. Morning milk was added at 07:30 h, while evening milk was added at 18:00 h. In both conditions, water was used in place of milk and heated to $37{ }^{\circ} \mathrm{C}$ to mimic the temperature immediately after milking. The following day, the milk was discharged at 07:00 $\mathrm{h}$ and transported to the milk processing center in a single trip. This process reduces the farmers' transportation cost. The quality of the milk is not affected during transport as it is already below $4{ }^{\circ} \mathrm{C}$, unlike in the conventional method of taking milk directly to the processing center, which increases the possibility of a bacterial growth. As shown in Fig. 3, solar insolation is converted into electrical energy, which is used to operate the twin DC compressors of the milk chiller to produce cold thermal energy, which is then stored in the form of ice/TES in the IBT. This TES is used to chill $10 \mathrm{~L}$ of milk in the morning and evening.

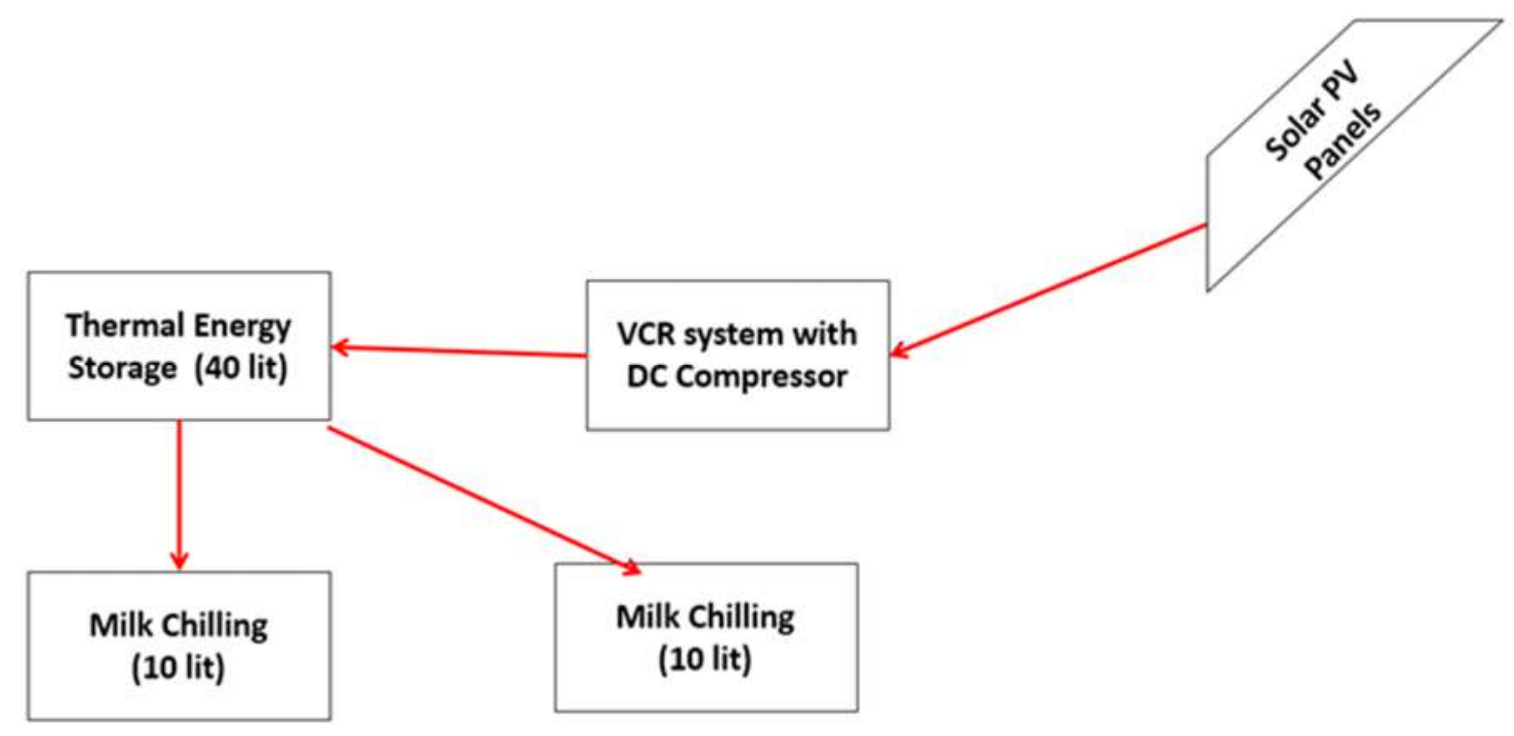

Fig. 3. Energy storage and energy release schedule 


\section{Performance analysis of a vapor compression based refrigeration unit}

The COP of a VCR-based milk chilling unit is defined as the ratio between the cooling capacity of the refrigeration unit and the electrical power consumed by the compressor and the condenser fan (Rajendran et al. 2019; Prabakaran et al. 2021).

$$
C O P=\frac{Q_{e v a p}}{\left(W_{e l e}+W_{F a n}\right)}
$$

where $\mathrm{Q}_{\text {evap, }} \mathrm{W}_{\text {ele }}$, and $\mathrm{W}_{\mathrm{Fan}}$ are the refrigeration capacity, compressor electrical power, and power used by the fan condenser, respectively. The refrigeration capacity can be calculated with the help of the refrigerant mass flow rate and enthalpy change across the cooling coil, as shown in Equation (2).

$$
Q_{\text {evap }}=\dot{m}_{r}\left(h_{\text {evap_out }}-h_{\text {evap_in }}\right)
$$

\section{Uncertainty analysis}

In this study, the temperature/pressure across each component of the unit, refrigerant mass flow rate, volume of overflow, voltage, current, ambient temperature, and solar insolation consumed by the compressors were measured to calculate the COP and power consumption. The uncertainties of the calculated parameters were estimated using the following equations (Moffat 1998). The uncertainties of COP and power consumption were found to be $5.57 \%$ and $5.6 \%$, respectively.

$$
\frac{\partial C O P}{T C O P}=\left[\left(\frac{\partial Q_{\text {evap }}}{Q_{\text {evap }}}\right)^{2}+\left(\frac{\partial \text { Power }}{\text { Power }}\right)^{2}\right]^{\frac{1}{2}}
$$

$$
\frac{\partial Q_{\text {evap }}}{Q_{\text {evap }}}=\left[\begin{array}{c}
\left(\frac{\partial T_{\text {evap_in }}}{T_{\text {evap_in }}}\right)^{2}+\left(\frac{\partial T_{\text {evap_out }}}{T_{\text {eva_out }}}\right)^{2}+\left(\frac{\partial P_{\text {evap } \_i n}}{P_{\text {evap_in }}}\right)^{2}+ \\
\left(\frac{\partial P_{\text {evap_out }}}{P_{\text {evap_out }}}\right)^{2}+\left(\frac{\partial m_{r}}{m_{r}}\right)^{2}
\end{array}\right]^{\frac{1}{2}}
$$

$$
\frac{\partial \text { Power }}{\text { Power }}=\left[\left(\frac{\partial V}{V}\right)^{2}+\left(\frac{\partial I}{I}\right)^{2}\right]^{\frac{1}{2}}
$$

\section{Results and discussion}

The performance of the milk chiller with a pair of DC compressors was continuously evaluated for 18 days for each of the three seasons in Chennai: monsoon, winter, and summer. Performance parameters such as seasonal solar insolation, compressor power consumption, ice formed, and temperatures across the VCR system components, system COP, and overall efficiency of the unit are discussed for each climatic season. 


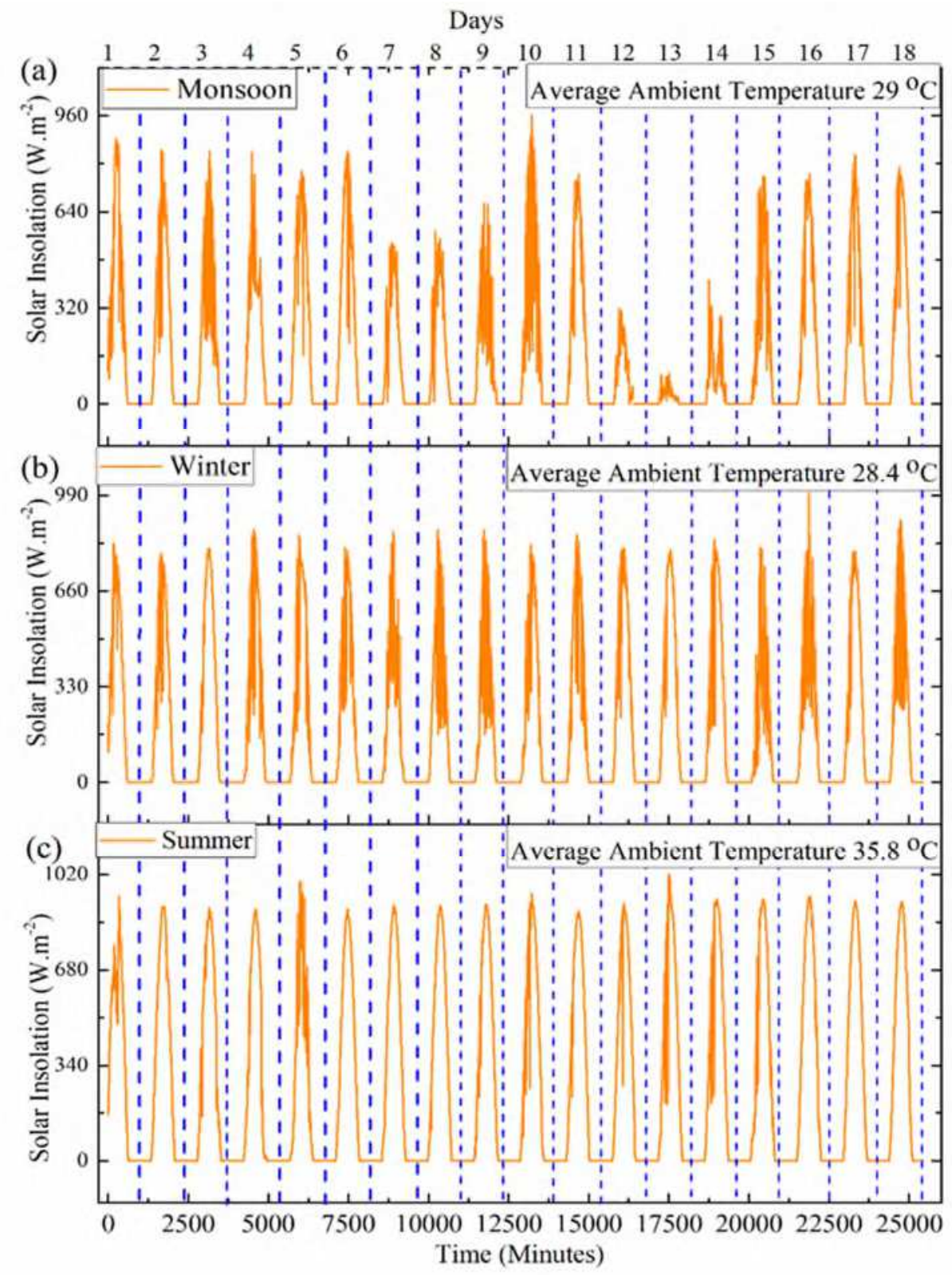

Fig. 4. Solar insolation and ambient temperature in Chennai, India during (a) monsoon, (b) winter, and (c) summer

Before analyzing the performance of the unit, the solar insolation for Chennai was measured and recorded from September 9 to 26, 2018 for the monsoon season; from January 22 to February 8, 2019 for the winter season; and from May 4 to 21, 2019 for the summer season. The solar insolation and average ambient temperatures for all seasons are shown in Fig. 4. In the monsoon season, the solar insolation was found to be less than 200 W.m ${ }^{-2}$ for days 12-14 because of the overcast conditions. During the monsoon season in Chennai, the average insolation and ambient temperature were observed to be $413.81 \mathrm{~W} \cdot \mathrm{m}^{-2}$ and $29{ }^{\circ} \mathrm{C}$, respectively. In the winter season, solar insolation was higher than that during the monsoon season because of clear sky conditions. In the winter season, the average solar insolation and ambient temperature were $532.66 \mathrm{~W} . \mathrm{m}^{-2}$ and $28.4{ }^{\circ} \mathrm{C}$, respectively. The summer season had the highest solar insolation and ambient temperatures compared to the other seasons. The average solar insolation and ambient temperature were $726.06 \mathrm{~W} \cdot \mathrm{m}^{-2}$ and $35.8{ }^{\circ} \mathrm{C}$, respectively. The overall seasonal operation of both refrigeration circuits is discussed in the following section. 


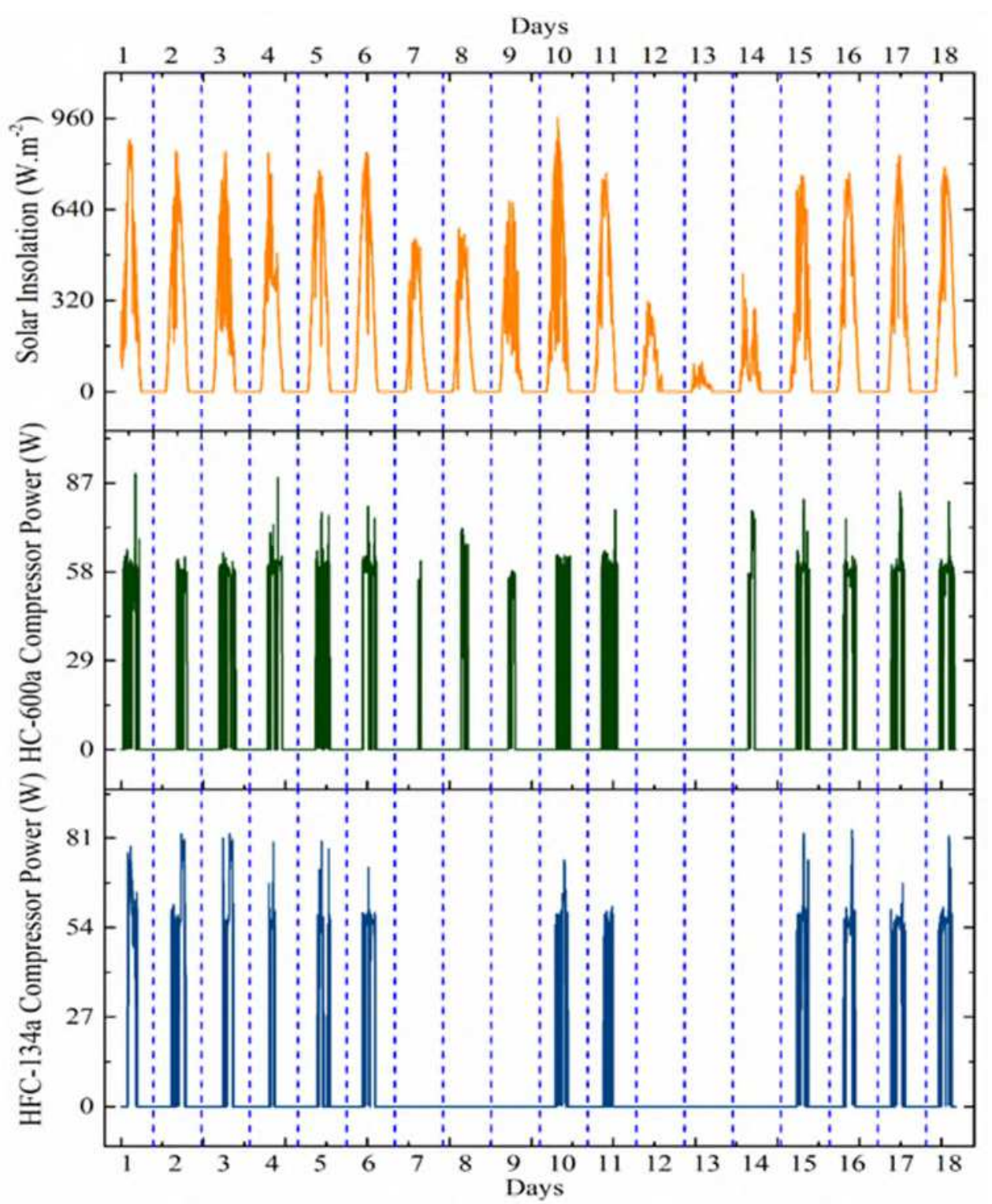

Fig. 5. Solar insolation and power consumption of the compressors during the monsoon season field test

The monsoon is a rainy season that is accompanied by overcast conditions. Figure 5 depicts the operation of both the HC-600a and HFC-134a compressors in the field application when powered with two PV panels (150 $\mathrm{W} / \mathrm{p}$ ) connected in parallel. The running time of the compressor was determined using solar insolation. The power consumption of the HFC-134a compressor was always higher than that of the HC-600a compressor; hence, it always started later when the insolation was sufficient. This could be because of a higher pressure ratio and refrigerant mass flow rate in HFC-134a than in HC-600a owing to its thermophysical properties (Joybari 2013). The average difference in power consumption between the HFC-134a and HC-600a compressors was 515 W. As seen in Fig. 5, only the HC-600a compressor was able to function during days 7, 8, 9, and 14; on days 12 and 13, both did not operate as the insolation was less than $250 \mathrm{~W} \cdot \mathrm{m}^{-2}$ because of the extremely overcast conditions. The effects of overcast conditions could be observed on ice formation in the IBT. The overall operation of the milk chiller was dependent on solar insolation. To analyze the performance of the milk chiller 
under different solar insolation conditions, three days were selected from the 18 days of experiments in the monsoon season to represent the days with the highest and lowest average solar insolation. The 5th day (September 13, 2018) had the highest average solar insolation during the monsoon season. The average solar insolation during this day was $624.08 \mathrm{~W} . \mathrm{m}^{-2}$.

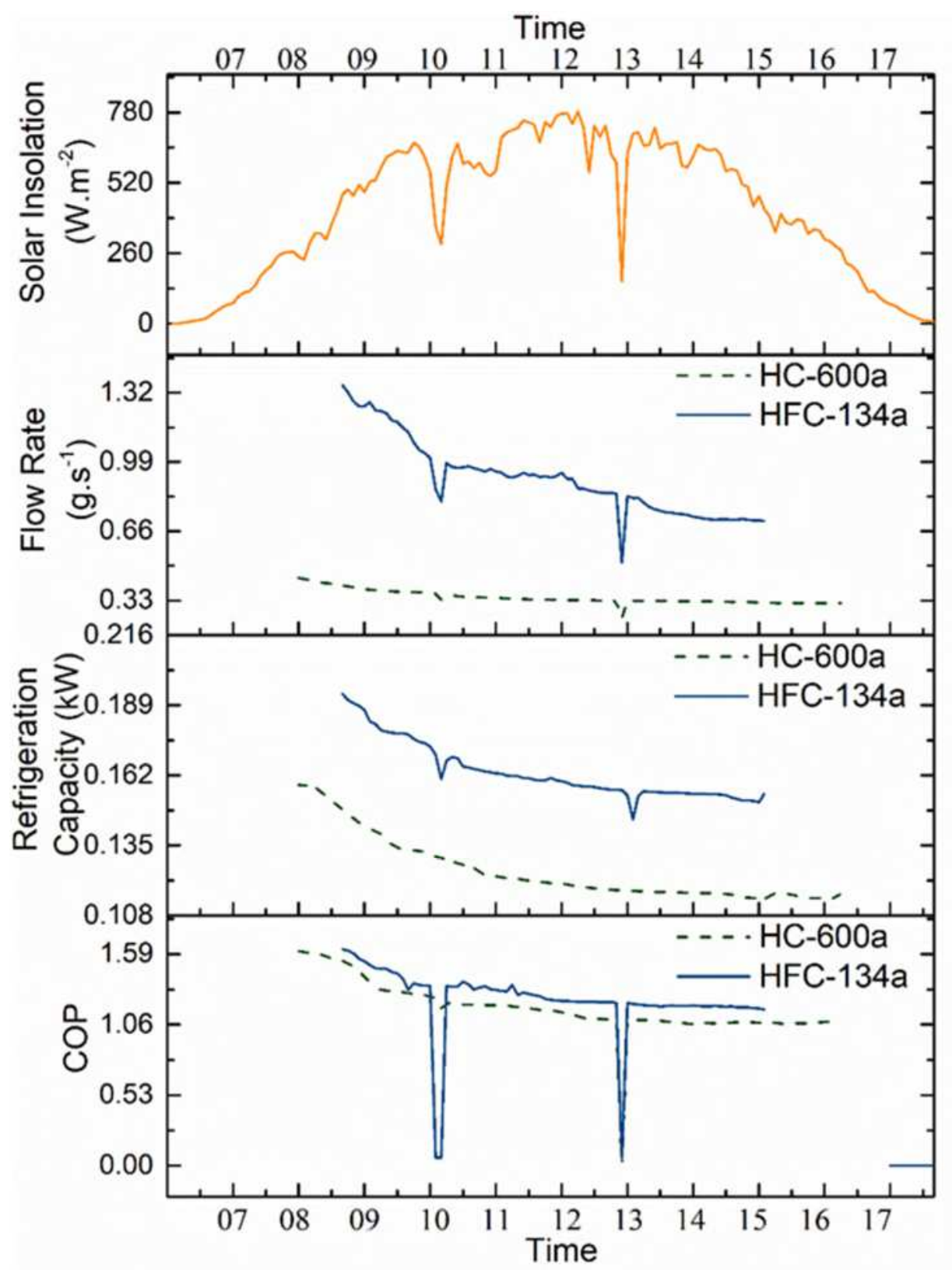

Fig. 6. Variation in solar insolation, refrigerant flow rate, refrigeration capacity, and COP for the day with the highest solar insolation (monsoon season)

Figure 6 depicts the solar insolation, refrigerant flow rate, refrigeration capacity, and COP of the day with the highest average solar insolation in the monsoon season. When the solar insolation crossed $250 \mathrm{~W} . \mathrm{m}^{-2}$, the HC600a compressor started at 08:05 h. When the solar insolation crossed $400 \mathrm{~W} . \mathrm{m}^{-2}$ the HFC-134a compressor also commenced working at 08:45 h. For both circuits, the refrigerant flow rate was observed to gradually reduce and stabilize as the heat load in the IBT decreased. The HFC-134a circuit was subjected to more cut-offs and cut-ins when the insolation decreased and increased, respectively. The average refrigerant flow rates of the 
HC-600a and HFC-134a circuits were 0.361 and 0.847 g.s ${ }^{-1}$, respectively. The flow rate of the HFC-134a circuit was $56.5 \%$ greater than that of the HC-600a circuit. In the evening, at 15:05 h, the HFC-134a circuit was the first to turn off, followed by the HC-600a compressor at 16:10 h. The total operation time of the HC-600a circuit was $485 \mathrm{~min}$, while the HFC-134a circuit was operational for only $345 \mathrm{~min}$.

Similar to the refrigerant flow rates, the refrigeration capacity gradually decreased and stabilized as the load decreased. The HFC-134a circuit had a higher refrigeration capacity than that of the HC-600a circuit, which could be because of the higher refrigerant flow rates experienced in the HFC-134a circuit. The average refrigeration capacity of the HFC-134a circuit was $0.161 \mathrm{~kW}$, whereas it was $0.129 \mathrm{~kW}$ for the HC-600a circuit, leading to a difference in refrigeration capacity of $19.4 \%$. At the end of the day, $10.1 \mathrm{~kg}$ of ice was available in the IBT. Initially, the COP was high because of the higher refrigeration capacity, and it gradually decreased and stabilized. The average COP of the HC-600a and HFC-134a circuits was 1.21 and 1.25, respectively. The COP of the HFC-134a circuit was $3.2 \%$ higher than that of the HC-600a circuit.

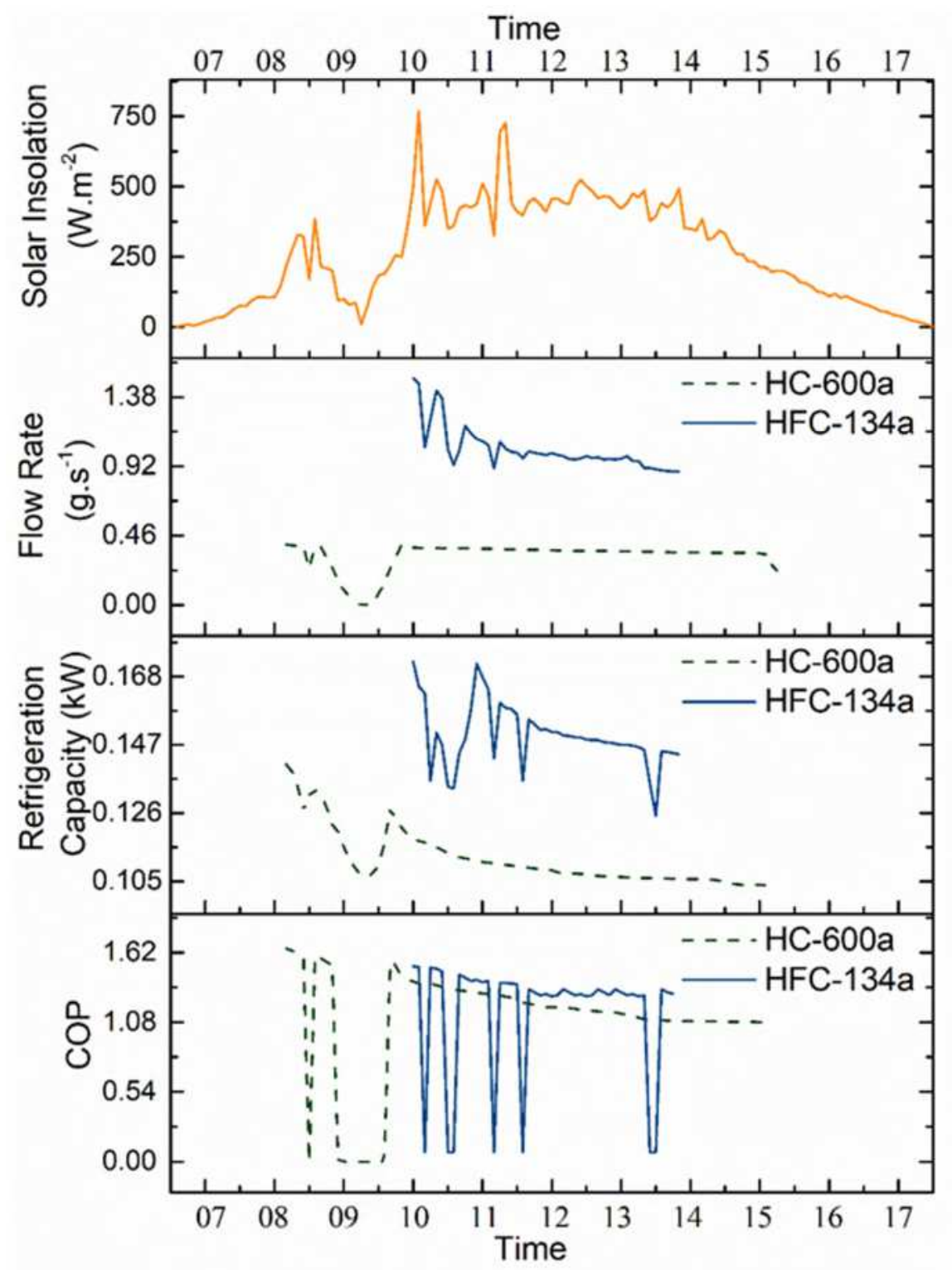

Fig. 7. Variation in solar insolation, refrigerant flow rate, refrigeration capacity, and COP for the day with the lowest solar insolation (monsoon season) 
From Fig. 5, it can be observed that the 13th day had the lowest solar insolation, with an average solar insolation of $36.09 \mathrm{~W} . \mathrm{m}^{-2}$. As none of the compressors could operate on that day, it was impossible to compare the performance of both refrigeration circuits under such conditions. Thus, the day with the lowest solar insolation, in which both compressors were operational, was selected; the 7th day (September 15, 2018), with an average solar insolation of $323.9 \mathrm{~W} \cdot \mathrm{m}^{-2}$. The solar insolation was observed to fluctuate excessively because of a cloud cover in the morning, but the sky was comparably clearer in the afternoon, as seen in Fig. 7. The flow rate in the HFC-134a circuit had more fluctuations than that in the HC-600a circuit; this was because of intermittent cloud cover, which reduced the solar insolation. The average flow rates in the HC-600a and HFC-134a circuits were 0.324 and 0.771 g.s $\mathrm{s}^{-1}$, respectively. The flow rate in the HFC-134a circuit was $58 \%$ higher than that in the HC-600a circuit. The HC-600a compressor started working at 08:05 h, while the HFC-134a circuit started at 10:00 h. The HFC-134a compressor was the first to turn off completely at 13:55 h, while the HC-600a compressor turned off at 15:00 h. The total operation time for the HC-600a circuit was 330 min, while it was 195 min for the HFC-134a circuit.

The effect of the variation in the refrigerant flow rate was observed in the refrigeration capacity of both circuits. The average refrigeration capacities of the HC-600a and HFC-134a circuits were 0.114 and $0.128 \mathrm{~kW}$, respectively. The refrigeration capacity of HFC-134a was $10.9 \%$ higher than that of HC-600a because of the higher refrigerant flow rate. The COP of both circuits was observed to be zero when the solar insolation was below $400 \mathrm{~W} . \mathrm{m}-2$ for the HFC-134a circuit and below $250 \mathrm{~W} . \mathrm{m}-2$ for the HC-600a circuit. The average COP of the HFC-134a circuit was 1.13, while that of the HC-600a circuit was 1.09, being $3.5 \%$ lower. At the end of the day, no ice was stored in the IBT.

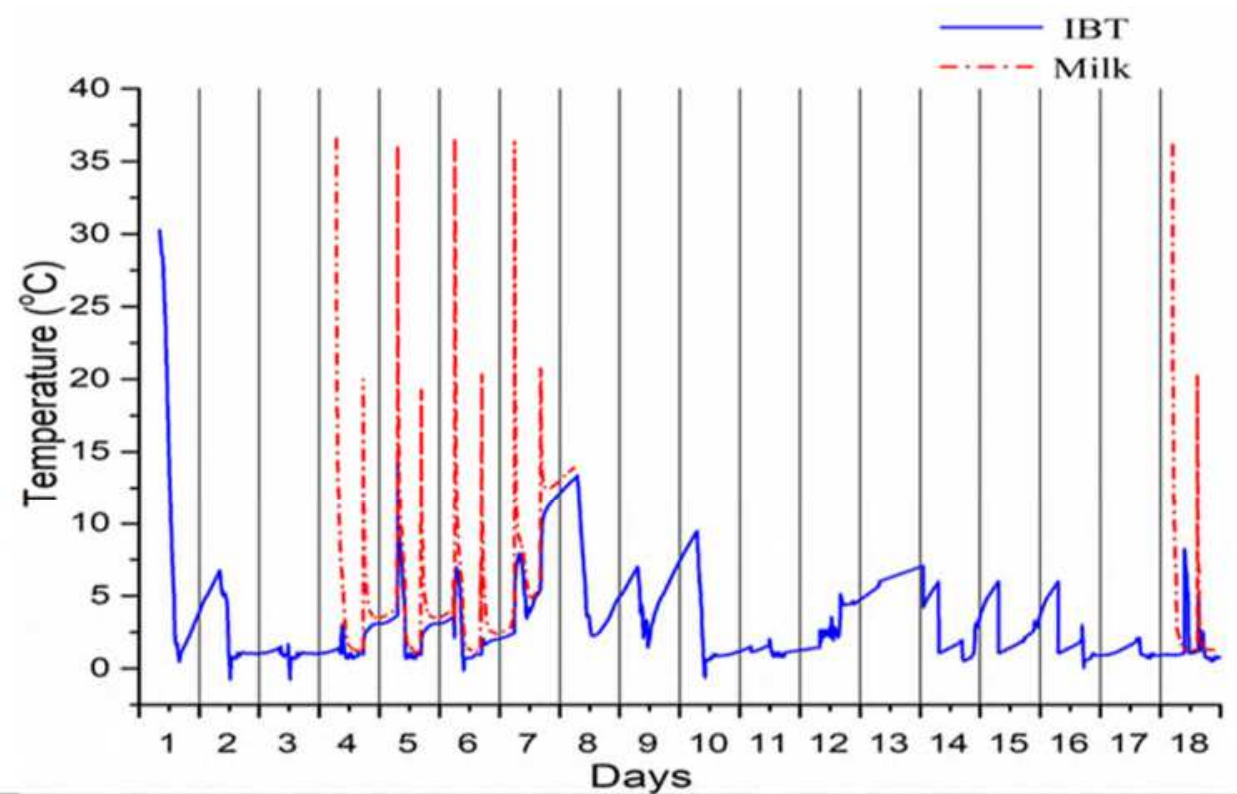

\begin{tabular}{|c|c|c|c|c|c|c|c|c|c|c|c|c|c|c|c|c|c|c|c|}
\hline \multicolumn{2}{|c|}{ Day } & 1 & 2 & 3 & 4 & 5 & 6 & 7 & 8 & 9 & 10 & 11 & 12 & 13 & 14 & 15 & 16 & 17 & 18 \\
\hline \multicolumn{2}{|c|}{ Ice at end of day (kg) } & 0 & 4.1 & 6.8 & 5.5 & 10.1 & 8.6 & 0 & 0 & 0.1 & 4.2 & 0 & 0 & 0 & 0 & 0 & 0 & 11 & 13.1 \\
\hline $\begin{array}{c}\text { Pull down } \\
\text { time of milk } \\
\text { (minutes) }\end{array}$ & Morning & - & - & - & 120 & 135 & 100 & 110 & - & - & - & - & - & - & - & - & - & - & 95 \\
\cline { 2 - 41 } & - & - & - & 70 & 75 & 80 & - & - & - & - & - & - & - & - & - & - & - & 75 \\
\hline
\end{tabular}

Fig. 8. Pull-down characteristics during the monsoon season along with the quantity of ice formed and milk pull-down time 
Figure 8 shows the pull-down characteristics of the IBT and milk during the monsoon season, along with the quantity of ice formed per day and the time required for chilling milk in the morning and evening from 37 to 4 ${ }^{\circ} \mathrm{C}$. During the monsoon season, at the end of day 1 of operation, ice was not available in the IBT. This was because of low solar insolation, which resulted in few hours of operation for both compressors. At the end of day 2, $4.1 \mathrm{~kg}$ of ice was available in the IBT, but this was insufficient to chill $10 \mathrm{~L}$ of milk from 37 to $4{ }^{\circ} \mathrm{C}$; thus, milk was not added the next morning (3rd day). At the end of day $3,6.8 \mathrm{~kg}$ of ice was available in the IBT, which was sufficient to chill $10 \mathrm{~L}$ of milk to $4{ }^{\circ} \mathrm{C}$. On day 4 at $07: 00 \mathrm{~h}, 10 \mathrm{~L}$ of milk were added at $37^{\circ} \mathrm{C}$. Within 120 min, the milk was observed to reach $4{ }^{\circ} \mathrm{C}$, with cooling provided only from the cold thermal energy stored in the IBT. By the end of day 4, $5.5 \mathrm{~kg}$ of ice was available in the IBT. By 18:00 h, evening milk $(10 \mathrm{~L})$ was added at $37{ }^{\circ} \mathrm{C}$, and cooled to $4{ }^{\circ} \mathrm{C}$ within $70 \mathrm{~min}$. On day 5, the previous day's (4th day) milk was dispensed at 06:00 h. and transported to the milk processing center at a temperature below $4{ }^{\circ} \mathrm{C}$. This process reduces the transportation cost, as milk received from two different sessions can be transported in a single phase. The same procedure was repeated on successive days. On day 7, the solar insolation was low and only one compressor was observed to be operational; by the end of the day, no cold thermal energy was available in the IBT. The evening milk was added at $18: 00 \mathrm{~h}$. and reached a minimum temperature of $14{ }^{\circ} \mathrm{C}$ in $5 \mathrm{~h}$. Considering all 18 days of testing in the monsoon season, the IBT could support the chilling of milk for only 4.5 days, that is, for days 4-6, day 7 (morning milk only), and day 18. This was because of the overcast conditions during the monsoon season. The results elucidate that solely depending on the IBT for chilling milk during the monsoon season is insufficient, and that an external power supply is necessary.

The experimental results revealed that the operation time of HFC-134a was lower than that of the HC-600a circuit for all days. On days 7-9 and 14, only the HC-600a circuit was operational, and on days 12 and 13, neither compressor was able to operate because of an extremely low insolation. The overcast conditions impacted the overall operation and ice formation in the IBT. Four individual days were analyzed in detail to understand the milk chiller's performance: day 1 (day with maximum heat load), the day with the highest average solar insolation, and the day with the lowest average solar insolation.

For all the days considered, the power consumption was higher for the HFC-134a circuit, which also had higher refrigerant flow rate than the HC-600a circuit. The COP of the HFC-134a circuit was higher than that of the HC-600a circuit, as HFC-134a had a better refrigeration effect. The hours of operation of the HC-600a circuit were longer than those of the HFC-134a circuit for all days. For the day with the lowest average solar insolation, the HC-600a compressor was operational for $330 \mathrm{~min}$, while the HFC-134a was operational for only $195 \mathrm{~min}$. Out of all 18 days of testing in the monsoon season, milk could be chilled from 37 to $4{ }^{\circ} \mathrm{C}$ for only 4.5 days. This means that solely depending on the IBT without any power backup is not favorable in the monsoon season.

\section{Winter season field analysis}

The winter season in places like Chennai is characterized by cool ambient temperatures and a clear sky. In India, the winter season extends from December to February. In the present study, the winter field test was conducted from January 22 to February 8, 2019. Figure 9 shows the power consumed by both compressors during the winter season, along with the solar insolation. Generally, for all the days, the HC-600a compressor was observed to start first when the solar insolation was low in the morning (approximately $250 \mathrm{~W} . \mathrm{m}-2$ ). The 
HFC-134a compressor was observed to start once the solar insolation was above $400 \mathrm{~W} . \mathrm{m}-2$. On day 3 , the solar insolation was observed to be uniform, and the operation of both compressors was observed to be smooth. From the 7th to 9th day, as seen in Fig. 9, solar insolation was interrupted by some intermittent cloud cover, and the compressors were subjected to frequent cut-offs and cut-ins. When compared to the monsoon season, the operation of both compressors during the winter season was observed to be smoother because of better solar insolation, clearer sky, and lower ambient temperature. To analyze the performance of the milk chiller under different solar insolation conditions in the winter season, three days were selected from the 18 days of experiments. Each day represented a day with the highest and lowest average solar insolation.

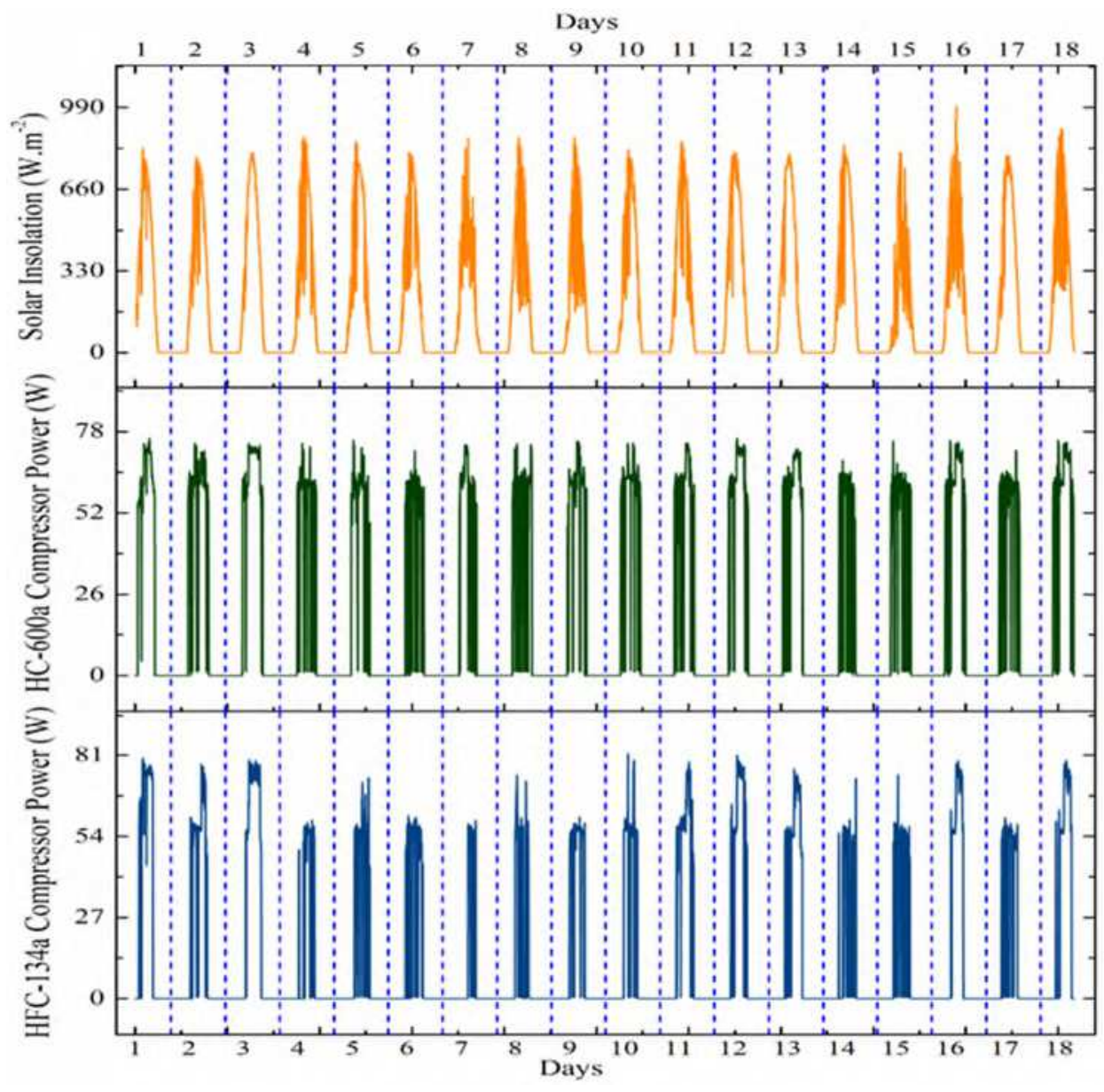

Fig. 9. Solar insolation and power consumption of the compressors during the winter season field test

The day with the highest average solar insolation during the winter season was the 3rd day of testing (January $24,2019)$. The average solar insolation during this day was $577.9 \mathrm{~W} \cdot \mathrm{m}^{-2}$. Figure 10 depicts the solar insolation, refrigerant flow rate, refrigeration capacity, and COP of the day with the highest solar insolation in the winter season. The solar insolation was observed to increase up to $300 \mathrm{~W} . \mathrm{m}^{-2}$, following which, owing to some minor cloud cover, it fell below $200 \mathrm{~W} . \mathrm{m}^{-2}$, after which clear sky was observed. As the solar insolation was reasonably high, both compressors could operate continuously and attain the peak operation speed. This was because of the inbuilt AEO unit, which controlled the speed of the compressor and helped it to directly attain the peak speed of $3500 \mathrm{rpm}$ within an hour with sufficient power (Danfoss 2009). In both circuits, the refrigerant flow rate was observed to gradually reduce and stabilize with a reduced heat load in the IBT. A significant reduction in flow 
rate could be seen as ice was already present in the IBT. The average refrigerant flow rates of the HC-600a and HFC-134a circuits were 0.422 and 1.022 g.s ${ }^{-1}$, respectively. The flow rate of the HFC-134a circuit was 58.7\% higher than that of the HC-600a circuit. The trend of the refrigeration capacity gradually stabilized, and thus, matched that of the refrigerant flow rate. The average refrigeration capacity of the HFC-134a circuit was 0.192 $\mathrm{kW}$, whereas that of the HC-600a circuit was $0.139 \mathrm{~kW}$. The average refrigeration capacity of the HFC-134a circuit was $27.6 \%$ higher than that of the HC-600a circuit. This could be because of the higher refrigerant flow rate in the HFC-134a circuit.

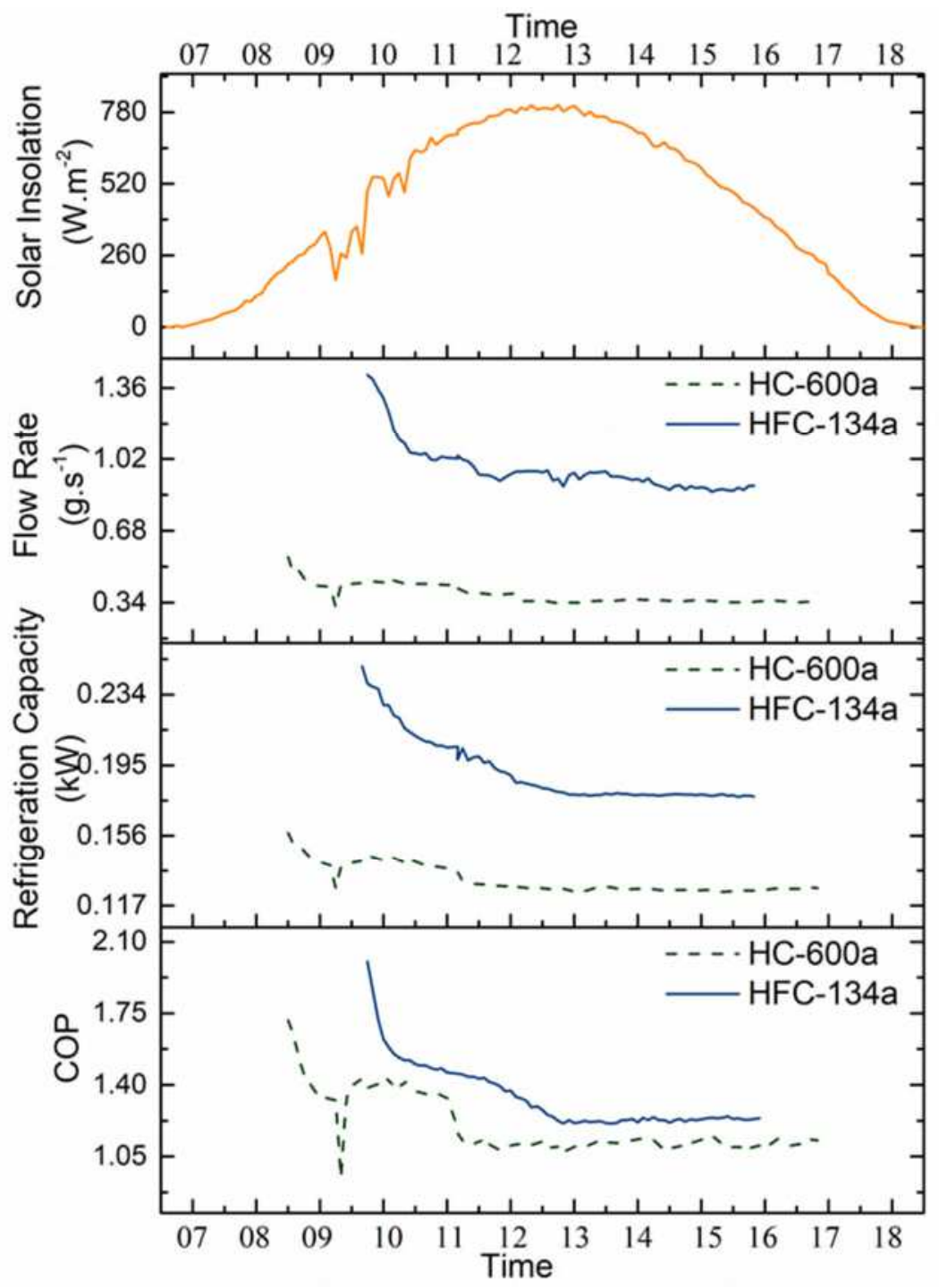

Fig. 10. Variation in solar insolation, refrigerant flow rate, refrigeration capacity, and COP for the day with the highest solar insolation (winter season)

The COP of the HFC-134a circuit was higher than that of the HC-600a circuit. This could be because of the higher refrigeration effect of the HFC-134a circuit. The average COP of the HFC-134a circuit was 1.25 while it was 1.34 for the HC-600a circuit. The average COP of the HFC-134a circuit was $7.72 \%$ higher than that of the HC-600a circuit. The HC-600a compressor started at 08:30 h, while the HFC-134a compressor started at 09:45 h. While the HFC-134a compressor turned off by 15:50 h because of low insolation, the HC-600a circuit turned 
off by 16:45 h. The total operation time of the HC-600a circuit was 505 min, while the HFC-134a circuit was operational for only $375 \mathrm{~min}$. The extra hours of operation of the HC-600a circuit could balance the difference in refrigeration capacity and COP. At the end of the day, $24.4 \mathrm{~kg}$ of ice was available in the IBT.

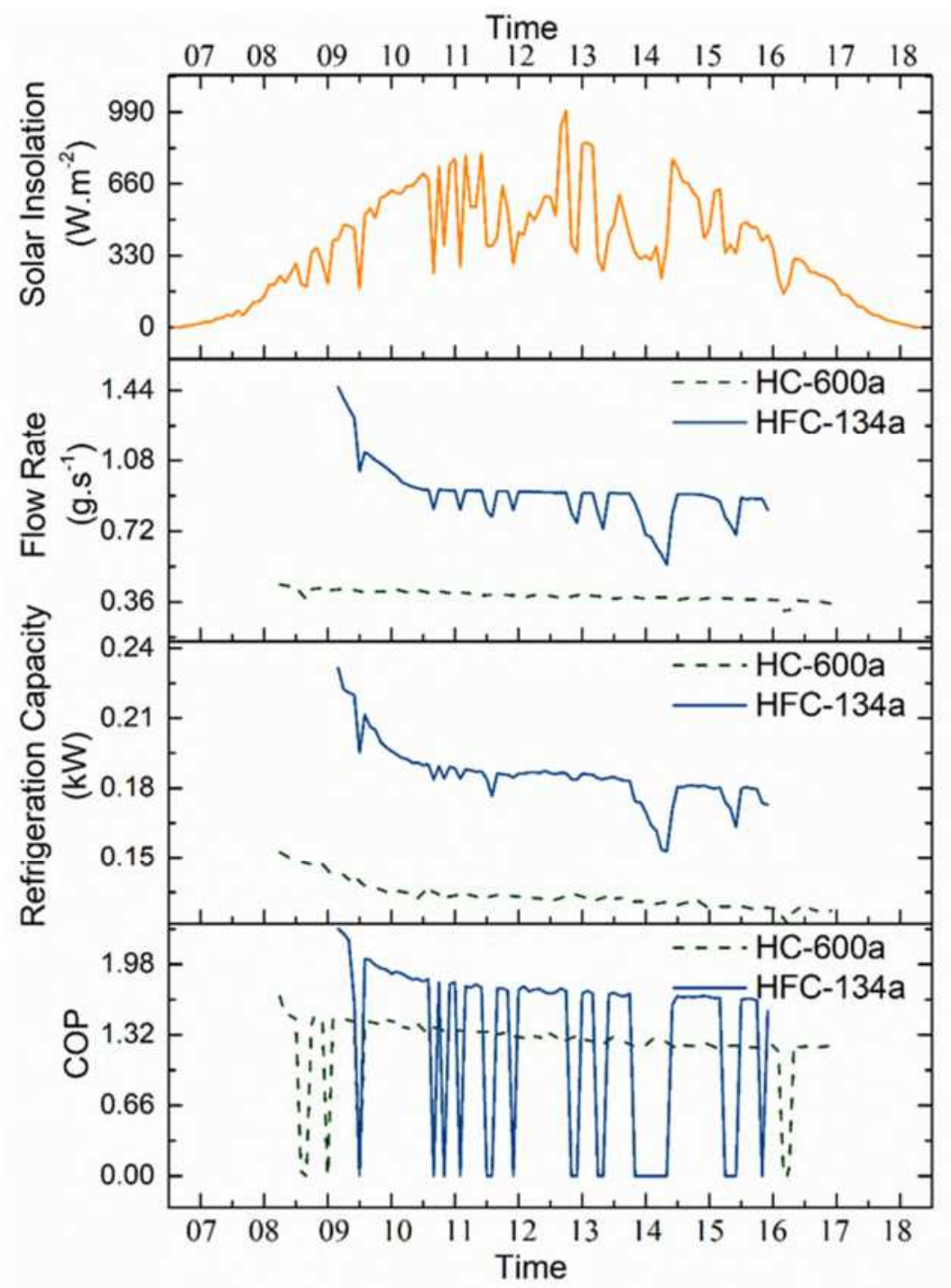

Fig. 11. Variation in solar insolation, refrigerant flow rate, refrigeration capacity, and COP for the day with the lowest solar insolation (winter season)

Figure 11 illustrates the solar insolation, refrigerant flow rate, refrigeration capacity, and COP of the day with the lowest solar insolation in the winter season, the 15th day of testing (February 5, 2019). The average solar insolation during this day was $353.9 \mathrm{~W} . \mathrm{m}^{-2}$. Similar to that in other conditions, the HC-600a compressor was the first to start at 08:15 h, while the HFC-134a compressor started at 09:10 h. HFC-134a stopped at 15:50 h and HC-600a stopped at 16:55 h. The HC-600a circuit was operational for 495 min, whereas the HFC-134a circuit was operational for only $300 \mathrm{~min}$. The average refrigerant flow rates of the HC-600a and HFC-134a circuits were 0.392 and 0.912 g.s $\mathrm{s}^{-1}$, respectively. The average flow rate was $57.1 \%$ higher in the HFC-134a circuit than in the HC-600a circuit. 
The trends of the refrigeration capacity of both circuits matched those of the refrigerant flow rate. The average refrigeration capacity of the HFC-134a circuit was $0.186 \mathrm{~kW}$, whereas it was $0.134 \mathrm{~kW}$ for the HC600a circuit. This shows that the average refrigeration capacity of the HFC-134a circuit was $27.9 \%$ higher than that of the HC-600a circuit. This could be because of the higher refrigerant flow rate of the HFC-134a circuit than that of the HC-600a circuit. The COP trends were observed to decrease and stabilize with time and matched those of the refrigeration capacity. The average COP of the HFC-134a circuit was 1.30, while that of the HC600a circuit was 1.22. The COP of the HFC-134a circuit was 6.2\% higher than that of the HC-600a circuit. At the end of the day, $25.5 \mathrm{~kg}$ of ice was available in the IBT.

The trends of refrigerant flow rate, refrigeration capacity, and COP for all three conditions (highest and lowest) were observed to gradually decrease and stabilize with time. The refrigerant flow rate, refrigeration capacity, and COP were found to be higher in the HFC-134a circuit than in the HC-600a circuit. The HC-600a circuit was observed to operate for a longer duration as it could operate at a lower solar insolation (minimum $250 \mathrm{~W} \cdot \mathrm{m}^{-2}$ ) than the HFC-134a circuit. The refrigeration capacity and COP were observed to be better than those during the monsoon season because of a clearer sky with lower cloud cover.

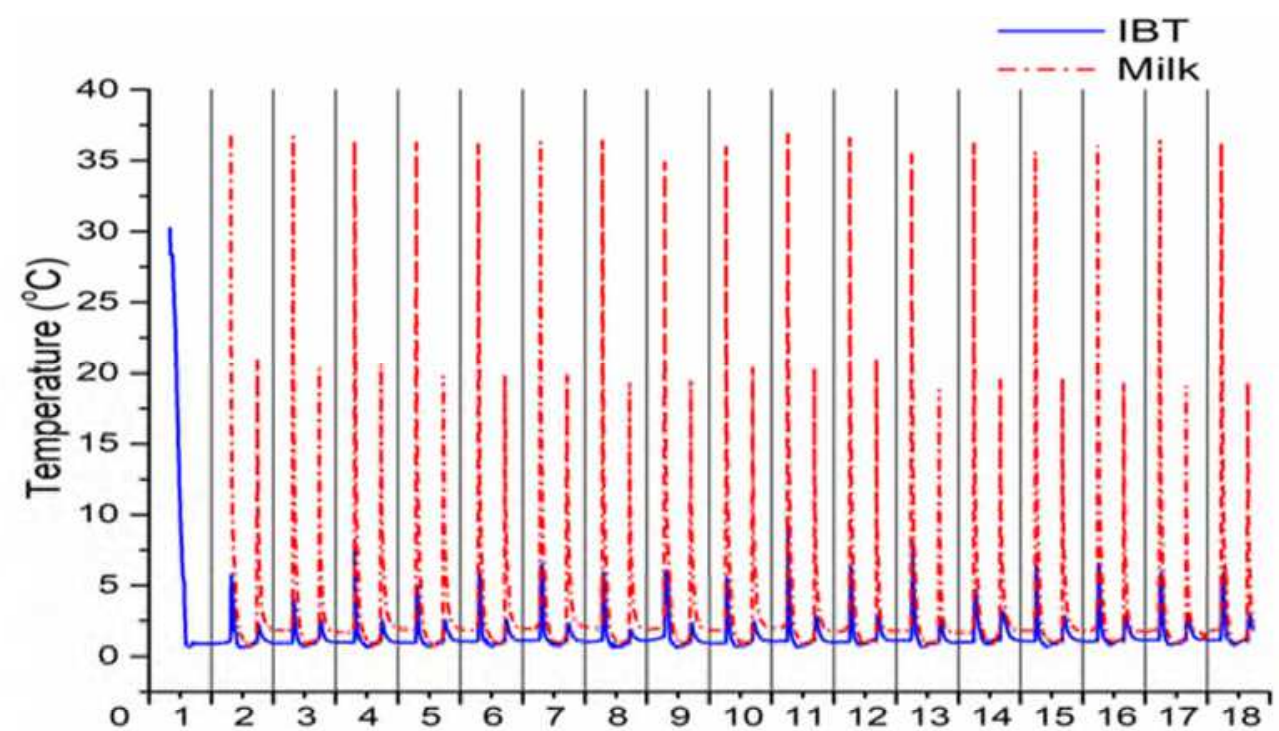

\begin{tabular}{|c|c|c|c|c|c|c|c|c|c|c|c|c|c|c|c|c|c|c|c|}
\hline & & \multicolumn{18}{|c|}{ Days } \\
\hline \multicolumn{2}{|c|}{ Day } & 1 & 2 & 3 & 4 & 5 & 6 & 7 & 8 & 9 & 10 & 11 & 12 & 13 & 14 & 15 & 16 & 17 & 18 \\
\hline \multicolumn{2}{|c|}{ Ice at end of day (kg) } & 8.7 & 18.5 & 24.4 & 23.1 & 24.8 & 23.1 & 19 & 15.9 & 17.6 & 21.1 & 27.9 & 29 & 25.5 & 26.6 & 25.5 & 25.1 & 24.8 & 24.9 \\
\hline \multirow{2}{*}{$\begin{array}{l}\text { Pull down } \\
\text { time of milk } \\
\text { (minutes) }\end{array}$} & Morning & - & 95 & 68 & 77 & 65 & 63 & 66 & 61 & 68 & 71 & 70 & 61 & 65 & 66 & 66 & 64 & 68 & 62 \\
\hline & Evening & - & 55 & 43 & 46 & 44 & 46 & 46 & 43 & 44 & 45 & 43 & 40 & 44 & 45 & 40 & 44 & 46 & 44 \\
\hline
\end{tabular}

Fig. 12. Pull-down characteristics during the winter season along with the quantity of ice formed

Figure 12 shows the pull-down characteristics of the IBT and milk tank along with the amount of ice formed at the end of each day. The hours of operation of the compressors were higher than those during the monsoon season, which enabled an increased level of cold TES in the IBT. At the end of day $1,8.73 \mathrm{~kg}$ of ice was available in the IBT. On day 2, at 07:00 h, $10 \mathrm{~L}$ of milk was added at $37{ }^{\circ} \mathrm{C}$ and it was observed to chill to $4{ }^{\circ} \mathrm{C}$ within $55 \mathrm{~min}$. At the end of day 2, the quantity of ice available in the IBT was $18.5 \mathrm{~kg}$. At 18:00 h, $10 \mathrm{~L}$ of milk was added at $37{ }^{\circ} \mathrm{C}$ in the evening. When the evening milk was mixed with morning milk, the milk 
temperature rapidly dropped to approximately $20{ }^{\circ} \mathrm{C}$, and then, uniformly chilled to $4{ }^{\circ} \mathrm{C}$ within 35 min. From day 1 onward, the quantity of ice formed in the IBT was observed to increase, but after the 6th day, this trend was observed to be affected by some intermittent cloud cover. However, after the 9th day, the quantity of ice formed was observed to increase again. After the 10th day, the amount of ice formed was observed to be greater than $25 \mathrm{~kg}$. The average pull-down time of the morning milk was found to be $40.1 \mathrm{~min}$, while the average pulldown time of evening milk was $26.5 \mathrm{~min}$. Owing to good solar insolation, a surplus amount of cold thermal energy was stored in the IBT in the form of ice every day, which enabled the system to operate without any battery backup during the winter season. In the case of overcast conditions, the surplus amount of cold thermal energy stored in the IBT could effectively cool the milk without battery backup.

\section{Summer season field analysis}

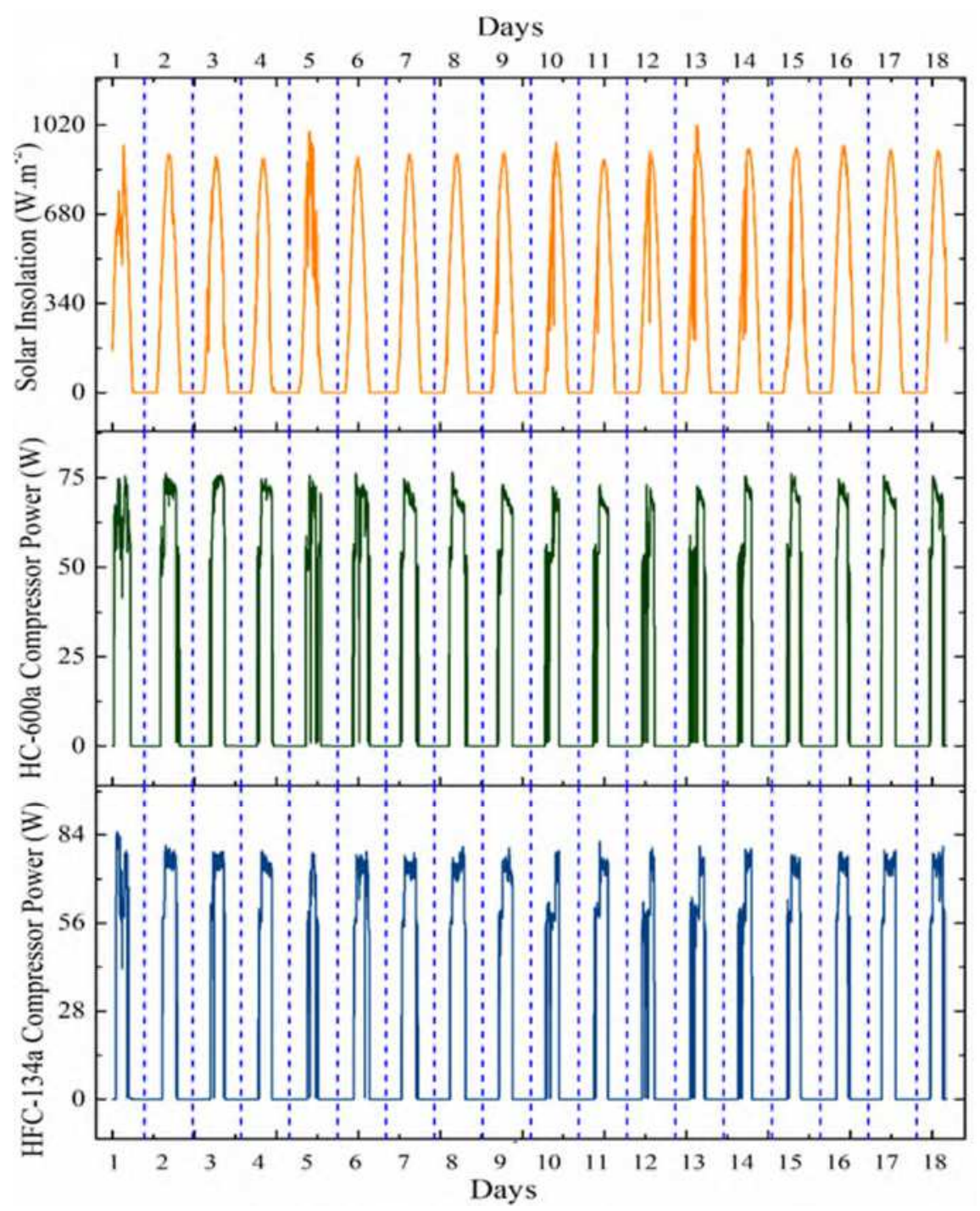

Fig. 13. Solar insolation and power consumption of the compressors during the summer season field test

In Chennai, the summer season generally has a clear sky and high ambient temperatures. The summer season in Chennai occurs from March to May and can be possibly extended in the case of a delay in the monsoon rains. Figure 13 shows the power consumed by the compressors during the summer season for the HC-600a and HFC- 
134a circuits. The summer season has longer days, which results in more hours of solar insolation, which leads to longer hours of operation for the compressors. As shown in Fig. 13, the average solar insolation is more than $400 \mathrm{~W} \cdot \mathrm{m}^{-2}$, and thus, both compressors could operate smoothly. In the summer seasons, on some days, such as day 5, the solar insolation was observed to reduce because of intermittent cloud cover, resulting in intermittent cut-offs and cut-ins for both compressors.

\section{Time}

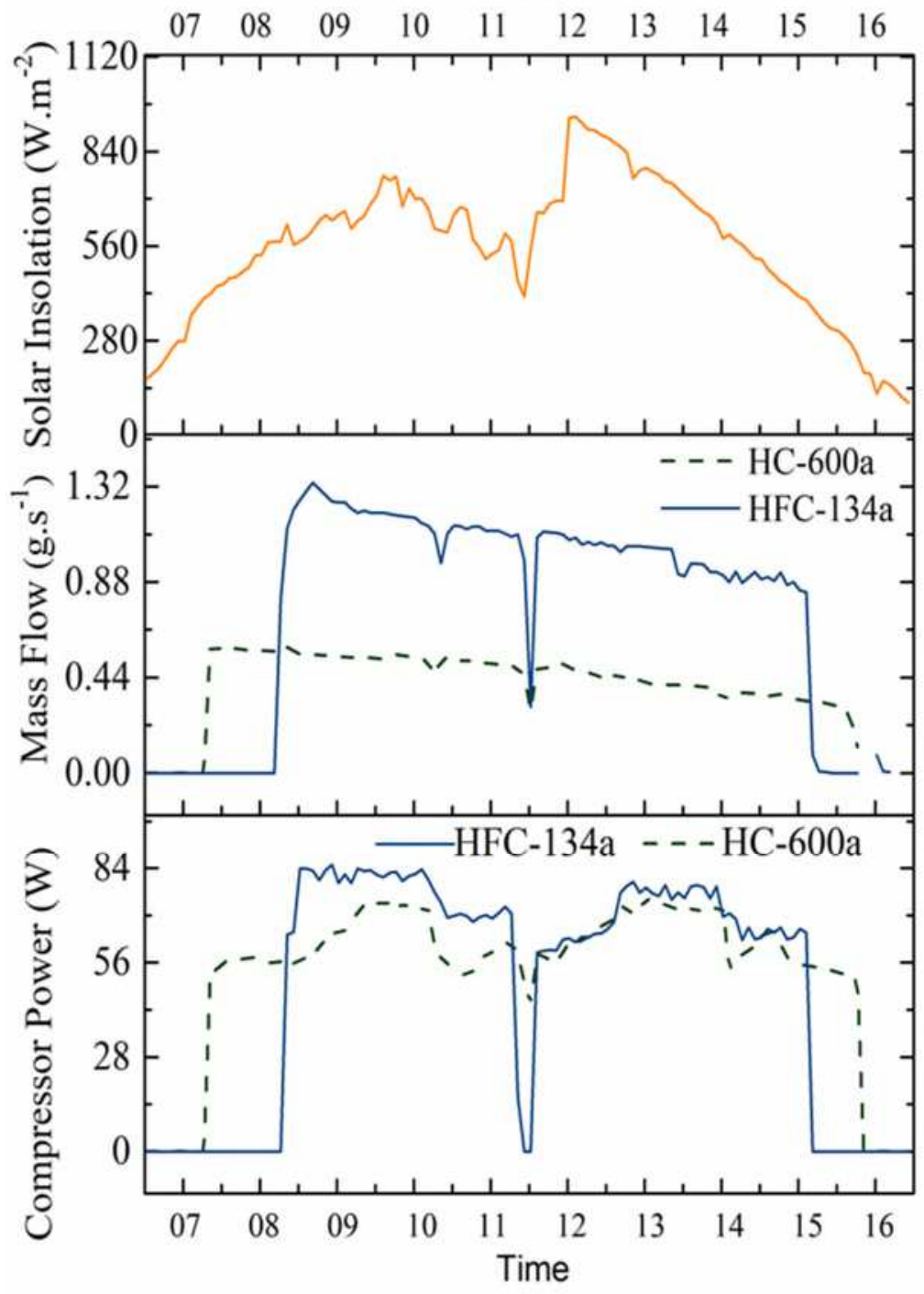

Fig. 14. Variation in solar insolation, refrigerant mass flow, and compressor power in the summer season (May 4, 2019)

Figure 14 shows the variation in solar insolation, refrigerant mass flow rate, and power consumed by each compressor for day 1 in the summer season. Similar to other seasons, the HC-600a compressor was observed to start first at 08:10 h, when the insolation crossed $250 \mathrm{~W} . \mathrm{m}^{-2}$. This was followed by the start of the HFC-134a circuit when the insolation crossed $400 \mathrm{~W} \cdot \mathrm{m}^{-2}$ at 09:10 h. The HFC-134a circuit stopped at 16:10 h, while the HC-600a circuit stopped at 16:50 h. The overall operating time of the HC-600a circuit was 510 min, whereas the HFC-134a circuit was operational for only $400 \mathrm{~min}$. The trends of the refrigerant mass flow rate and power consumption were similar to those in the other two seasons, except that both compressors operated for more hours. 
Variations in the refrigerant temperatures at various locations in the HFC-134a and HC-600a circuits were considered only for the summer season, as shown in Fig. 15. In this season, the number of cut-offs because of overcast conditions was lower than that in other seasons. This shows that the refrigerant temperature at the compressor outlet increased with time, whereas the temperature at the compressor and evaporator inlets decreased for both circuits. At about 12:30 h, the HFC-134a compressor turned off because of the cloudy conditions, which caused a drop in temperature at the compressor outlet and a corresponding increase in the evaporator inlet temperature. Compared to the HC-600a circuit, the drop in the evaporator temperature was faster for the HFC-134a circuit, and the temperature reached $0{ }^{\circ} \mathrm{C}$ by $09: 30 \mathrm{~h}$. For the HC-600a circuit, $0{ }^{\circ} \mathrm{C}$ was attained at 12:45 h. This could be because of the higher refrigerant mass flow rate in the HFC-134a circuit than in the HC-600a circuit. Similar to the other two seasons, two days were selected to represent days with the highest and lowest solar insolation from the 18 days of field experiments in the summer season.

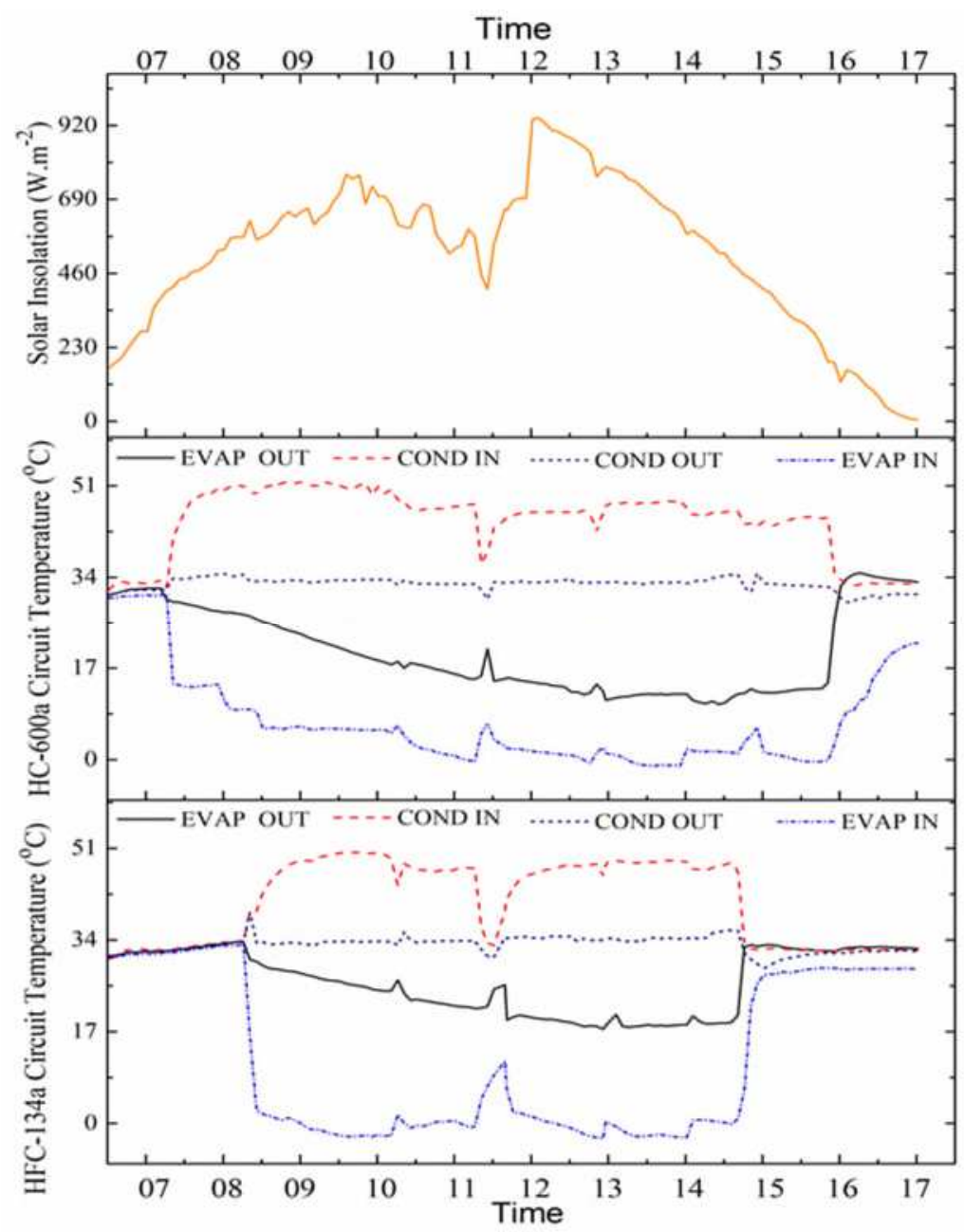

Fig. 15. Refrigerant temperature across each component in the HFC-134a and the HC-600a circuits during the summer season (May 4, 2019)

Figure 16 depicts the solar insolation, refrigerant flow rate, refrigeration capacity, and COP for the day with the highest solar insolation in the summer season, the 17th day of testing (May 20, 2019). The average solar insolation during this day was $731.3 \mathrm{~W} . \mathrm{m}^{-2}$. On this particular day, there was no cloud cover, and the solar insolation was observed to uniformly increase until noon and gradually decrease toward the evening. During 
such conditions, the compressors performed consistently at a peak speed of $3500 \mathrm{rpm}$ because of the AEO control unit. In both circuits, the refrigerant flow rate was observed to gradually decrease and stabilize because of a reduction in the heat load in the IBT. The refrigerant flow rate was higher in the HFC-134a circuit than in the HC-600a circuit. The HC-600a compressor started first at 07:15 h. This was followed by the HFC-134a circuit at 08:20 h. Both compressors cut off at the same time from the 7th day onward, by 14:30 h. The milk temperature was observed to be below $1{ }^{\circ} \mathrm{C}$, and both compressors turned off automatically because of the thermostat settings to ensure that milk was not frozen. The average refrigerant flow rates of the HC-600a and HFC-134a circuits were 0.454 and $1.22 \mathrm{~g} . \mathrm{s}^{-1}$, respectively. The average flow rate of the HFC-134a circuit was $62.8 \%$ higher than that of the HC-600a circuit. The trends of the refrigeration capacity were observed to match those of the refrigerant flow rate; they gradually decreased and stabilized. The average refrigeration capacity of the HC-600a circuit was $0.15 \mathrm{~kW}$ and that of the HFC-134a circuit was $0.208 \mathrm{~kW}$, being $27.9 \%$ greater. This resulted in better cooling from the HFC-134a circuit. The COP of the HFC-134a circuit was higher than that of the HC-600a circuit. This could be because of the better refrigeration effect of the HFC-134a circuit. The average COP of the HFC-134a circuit was 1.45, while that of the HC-600a circuit was 1.34. The average COP of the HFC-134a circuit was $7.58 \%$ higher than that of the HC-600a circuit.

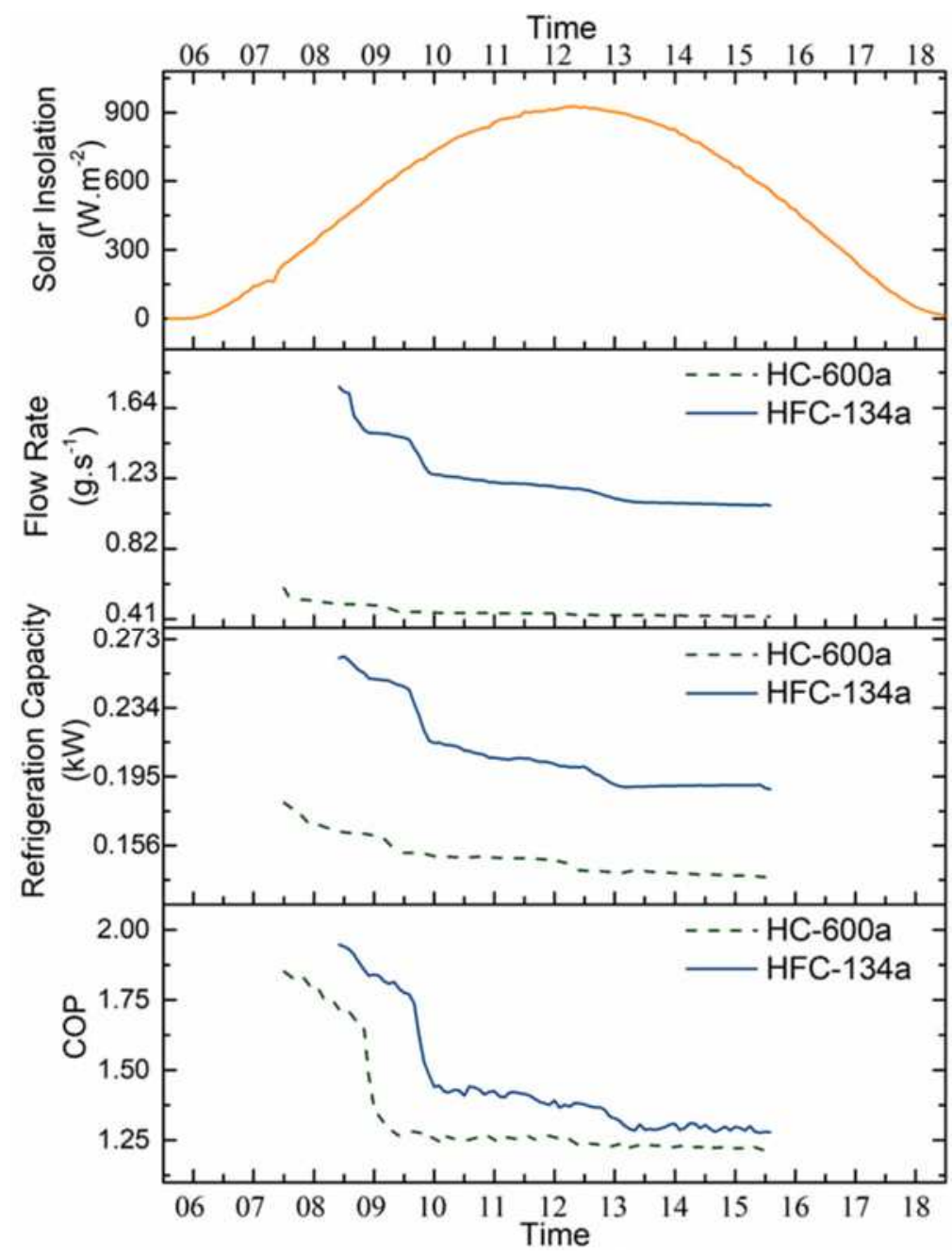

Fig. 16. Variation in solar insolation, refrigerant flow rate, refrigeration capacity, and COP for the day with the 


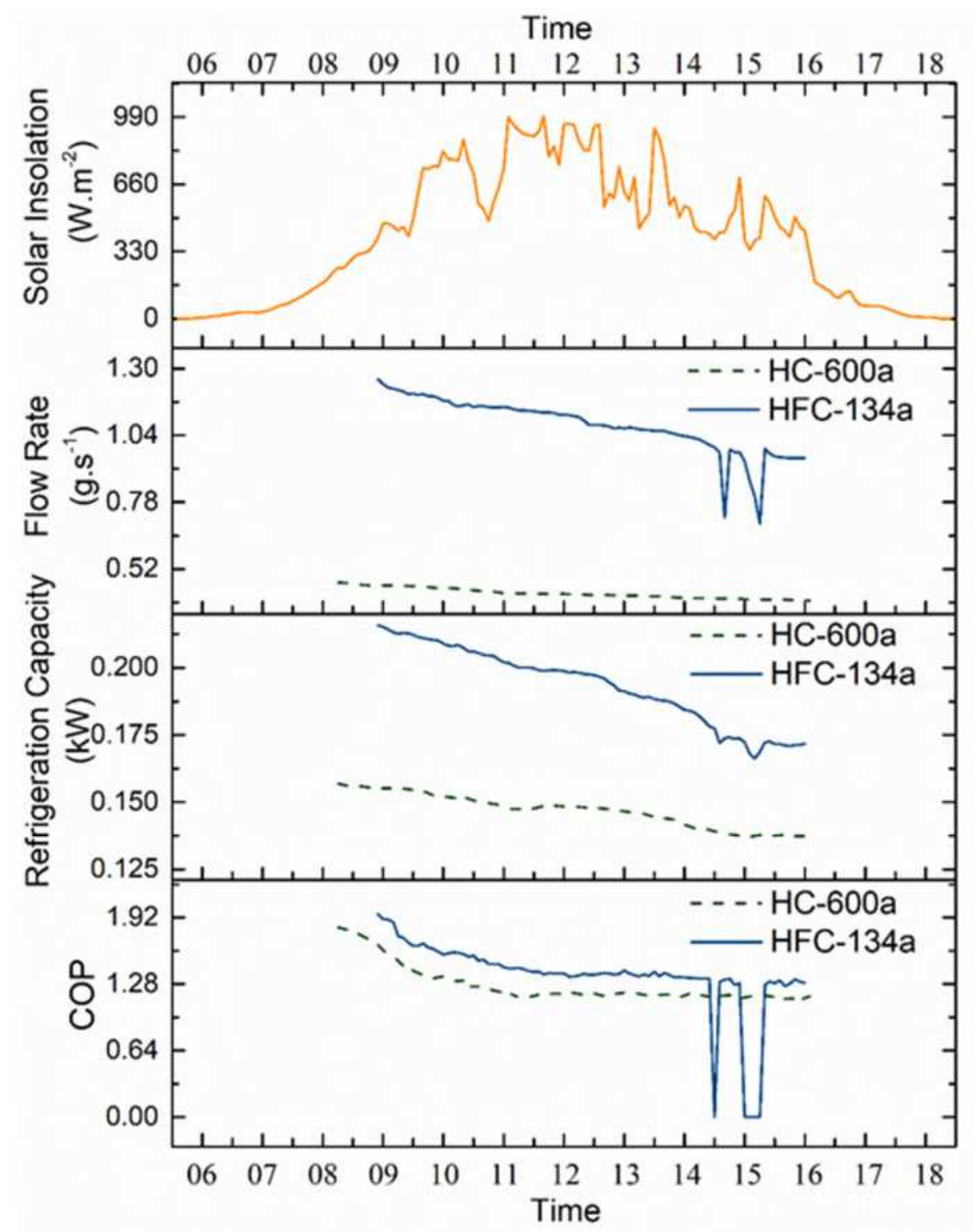

Fig. 17. Variation in solar insolation, refrigerant flow rate, refrigeration capacity, and COP for the day with the lowest solar insolation (summer season)

Figure 17 shows the solar insolation, refrigerant flow rate, refrigeration capacity, and COP of the day with the lowest solar insolation in the summer season, the 5th day of testing (May 8, 2019). The average solar insolation during this day was $573.1 \mathrm{~W} . \mathrm{m}^{-2}$. The solar insolation was observed to gradually increase when approaching noon, with some intermittent cloud cover. The solar insolation was consistently above $250 \mathrm{~W} \cdot \mathrm{m}^{-2}$, which facilitated the continuous operation of the HC-600a circuit, while the HFC-134a circuit had some intermittent cut-offs. The flow rate trends were observed to match those of other seasons. The average refrigerant flow rates of the HFC-134a and HC-600a circuits were 1.08 and $0.43 \mathrm{~g} . \mathrm{s}^{-1}$, respectively. The refrigerant flow rate of the HFC-134a circuit was $60.6 \%$ higher than that of the HC-600a circuit. The average refrigeration capacity of the HC-600a circuit was $0.141 \mathrm{~kW}$, and that of the HFC-134a circuit was $0.191 \mathrm{~kW}$, being $26.9 \%$ higher. This resulted in better cooling by the HFC-134a circuit, owing to the higher refrigerant 
The COP of the HFC-134a circuit was higher than that of the HC-600a circuit. The average COP of the HFC134a circuit was 1.27, while that of the HC-600a circuit was 1.37. The average COP of the HFC-134a circuit was $7.3 \%$ higher than that of the HC-600a circuit. The HC-600a circuit was operational from 08:15 to 16:05 h, while the HFC-134a circuit was operational from 09:00 to 16:00 h. The trends of refrigerant flow rate, refrigeration capacity, and COP for both conditions (highest and lowest solar insolation) gradually decreased and stabilized with time. The refrigerant flow rate, refrigeration capacity, and COP were found to be higher for the HFC-134a circuit than for the HC-600a circuit. The refrigeration capacity and COP were observed to be better than those during the monsoon and winter seasons because of the higher solar insolation in the summer season.

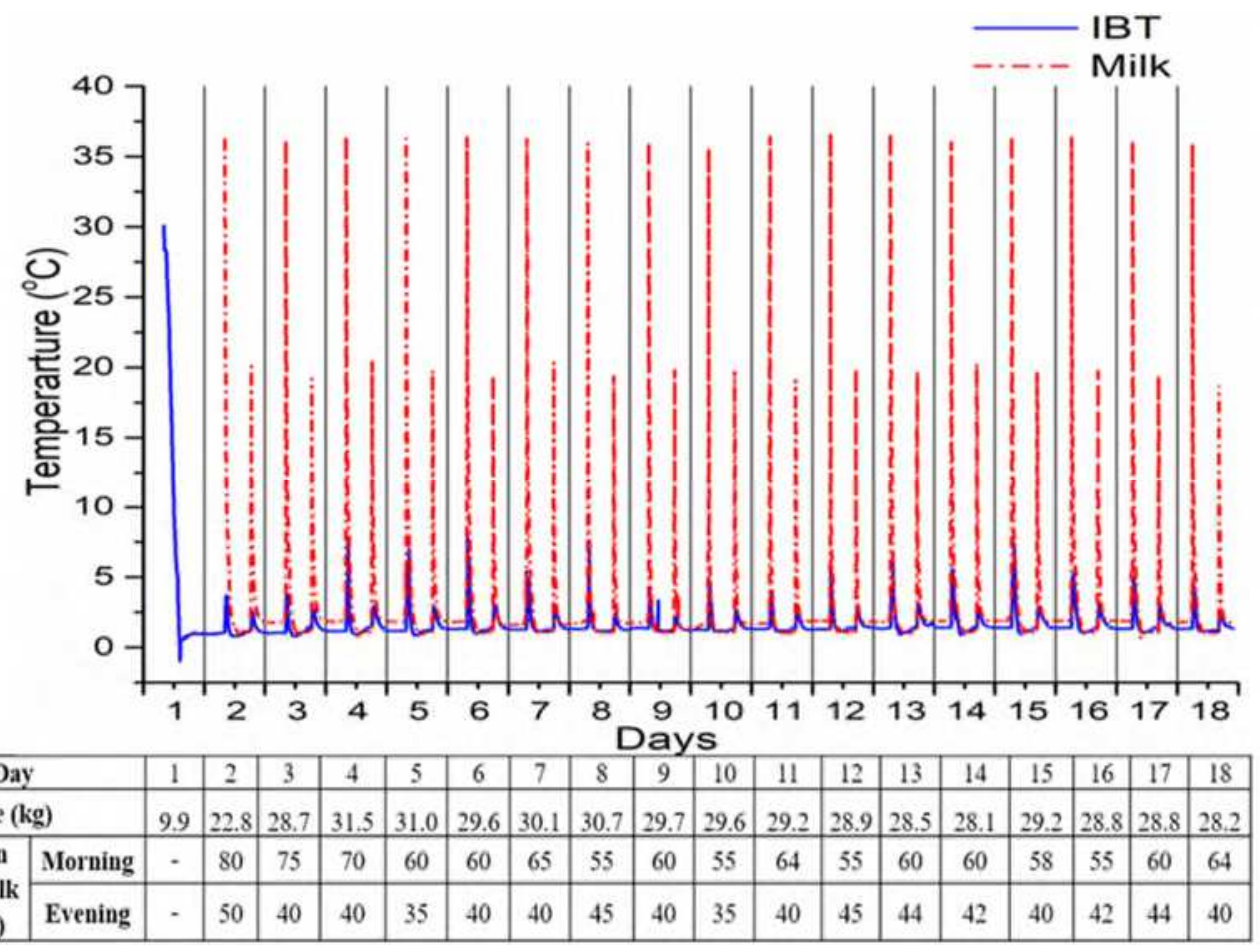

Fig. 18. Pull-down characteristics during the summer season along with the quantity of ice formed

The pull-down characteristics of the IBT and milk temperatures along with the quantity of ice formed during the 18 days of the study in the summer season are shown in Fig. 18. In the summer season, even though the ambient temperature was high, the performance of the PV panels was not significantly affected because of a high solar insolation. Owing to the good operating conditions and longer sunshine hours, a surplus of cold thermal energy was stored in the IBT as ice. From day 2 onward, more than $20 \mathrm{~kg}$ of ice was maintained in the IBT. After day 7, the milk temperature was observed to go below $1{ }^{\circ} \mathrm{C}$, and the compressor was cut off automatically because of the thermostat settings to avoid freezing the milk. Thus, after day 7 , as the compressors were cut off earlier, the power from the PV panels was not utilized. This excess power can be fed to the grid or used to charge solar-powered gadgets. In the summer season, the ambient temperatures were always higher, and consequently, the heat infiltration losses would also be higher. Owing to the surplus cold thermal energy stored in the IBT, the system could maintain the milk temperature below $4{ }^{\circ} \mathrm{C}$ in case of sudden rain or cloudy conditions for up to 2.5 days. 
Of all seasons, ice formation was the highest in the summer season, followed by that in the winter and monsoon seasons. The operation of the milk chiller depending solely on the IBT was observed to be feasible in the winter and summer seasons. In the monsoon season, however, battery backup would be necessary. The summer season also required the compressors to be cut off when the milk temperature was below $1{ }^{\circ} \mathrm{C}$. Thus, the power produced after the cut-off can be fed to the grid.

\section{Conclusions}

The feasibility of a novel twin-circuit (HFC-134a and HC-600a) DC compressor milk chiller with waterbased TES operated by solar PV was studied under different climatic conditions in Chennai, India. The test was conducted for 18 days continuously for each season, and the quantity of ice formed in the IBT was assessed for cooling milk from 37 to $4{ }^{\circ} \mathrm{C}$ twice a day. The average amount of ice formed per day in the TES during monsoon, winter, and summer seasons was found to be 3.61, 19.75, and $27.97 \mathrm{~kg}$, respectively. The experimental study revealed that ice formation and milk chilling time were the best in the summer season, followed by those in the winter and monsoon seasons. The operation of the milk chiller depending solely on the IBT is observed to be feasible in the winter and summer seasons; however, in the monsoon season, a battery backup is necessary. The use of two circuits is more advantageous than a single big system as it enables the operation of at least one compressor during low solar insolation. It was found that the HC-600a circuit consumed 5-15 W less than the HFC-134a circuit. However, the drop in the evaporator temperature is faster for the HFC-134a circuit. The running time of the HC-600a circuit is longer because it consumes less power and is capable of starting and operating at a lower solar insolation, making it operational for longer hours, which counterbalances its operational performance. The results from the summer season also show that the compressors automatically cut off when the milk temperature is below $1{ }^{\circ} \mathrm{C}$. The power produced after the cutoff can then be fed into the grid.

TES provided the stored cold thermal energy in the evening and the following morning for cooling raw milk. This circumvents the use of batteries and their supporting components, which aids in decreasing the overall system investment cost. The outcome of this study can promote the use of eco-friendly solar PV for rural milk chilling applications with comparatively lower initial costs using TES.

\section{Acknowledgements}

The authors would like to acknowledge the following:

- UGC-MANF (F1-17.1/2016-17/MANF-2015-17-TAM- 51497) India for the financial support.

- DST-SERB (EMR/2016/00159) for the financial support in developing the experimental setup.

- DST-FIST for the financial support in developing the psychrometric facility. 
Conceptualization DM. Lal; Methodology, S. Sidney and R. Prabakaran; Formal analysis, S. Sidney, R. Prabakaran and SC. Kim; writing—original draft preparation, S. Sidney; writing—review and editing, R. Prabakaran, SC. Kim and DM. Lal; Supervision, DM Lal.

Data availability: The datasets used and analysed during the current study are available from the corresponding author on reasonable request.

\section{Compliance with ethical standards}

Conflict of interest: The authors declare that they have no conflict of interest.

Ethical approval: Authors are attested that this paper has not been published elsewhere, the work has not been submitted simultaneously for publication elsewhere and the results presented in this work are true and not manipulated.

Consent to participate: All the individual participants involved in the study have received informed consent.

Consent to publish: The participant has consented to the submission of the study to the journal.

\section{References}

Albayati IM, Postnikov A, Pearson S, Bickerton R, Zolotas A, Bingham C (2020) Power and energy analysis for a commercial retail refrigeration system responding to a static demand side response. Elec. Power Ene. Sys. 117:105645.

Axaopoulos PJ, Theodoridis MP (2009) Design and experimental performance of a PV Ice-maker without battery. Sol. Energy 83:1360-1369.

Barthel C, Gotz T (2012) The overall worldwide saving potential from domestic refrigerators and freezers. Wupperal (Germany). http://www.bigee.net/ media/filer _ public/2012/12/04/bigee _ doc _ 2 _ refrigerators _ freezers _ worldwide _ potential_ 20121130.pdf.

Breen M, Upton J, Murphy MD (2020) Photovoltaic systems on dairy farms: Financial and renewable multiobjective optimization (FARMOO) analysis, App. Energy 278: 115534,

Coulomb D, Dupont JL, Pichard A (2015) 29th Informatory note on refrigeration technologies. In The Role of Refrigeration in the Global Economy; IIR document; IIR (International Institute of Refrigeration): Paris, France.

Daffallaha KO (2018) Experimental study of $12 \mathrm{~V}$ and 24V photovoltaic DC refrigerator at different operating conditions. Physica B: Condensed Matter. 545:237-244.

Danfoss Refrigeration and Air Conditioning Division (2009) Danfoss BD Compressors Direct Current and Multi Voltage Applications.

De Blas M, Appelbaum J, Torres JL, García A, Prieto E, Illanes R (2003) A refrigeration facility for milk cooling powered by photovoltaic solar energy. Prog. Photovolt. Res. Appl. 11:467-479. 
Devarajan Y, Nagappan B, Subbiah G, Kariappan E (2021) Experimental investigation on solar-powered ejector refrigeration system integrated with different concentrators. Environ Sci Pollut Res 28: 16298-16307.

Driemeier C, Zilles R (2010) An ice machine adapted into an autonomous photovoltaic system without batteries using a variable-speed drive. Prog. Photovolt. Res. Appl. 18:299-305.

El-Bahloul, AAM, Ali AHH, Ookawara S (2015) Performance and sizing of solar driven DC motor vapor compression refrigerator with thermal storage in hot arid remote areas. Energy Procedia 70: 634-643.

FAO \& WHO (2011). Codex Alimentarius - Milk and Milk Products, second edition. Rome, FAO and World Health Organization (WHO). http://www.fao.org/docrep/015/i2085e/i2085e00.pdf.

Fezai, S, Cherif, H, Belhadj, J (2021) Hybridization utility and size optimization of a stand-alone renewable energy micro-grid. Envi. Pro. Sus. Energy 40(3): e13542.

Gao Y, Ji J, Han K, Zhang F (2021) Comparative analysis on performance of PV direct-driven refrigeration system under two control methods. Int. J. Refrig. 127: 21-33.

Ghafoor A, Munir A (2015) Worldwide overview of solar thermal cooling technologies. Renew. Sustain. Energy Rev. 43:763-774.

Han Y, Li M, Wang Y, Li G, Ma X, Wang R, Wang L (2019) Impedance matching control strategy for a solar cooling system directly driven by distributed photovoltaics. Energy 168:953-965.

Joybari MM, Hatamipour MS, Rahimi A, Modarres FG (2013) Exergy analysis and optimization of R600a as a replacement of R134a in a domestic refrigerator system. Int. J. Refrig. 36:1233-1242.

Kabeel A, Abdelgaied M, Al-Ali M (2018) Energy saving potential of a solar assisted desiccant air conditioning system for different types of storage. Envi. Pro. Sus. Energy 37:1448-1454.

Kamalapur GD, Udaykumar RY (2011) Rural electrification in India and feasibility of Photovoltaic Solar Home Systems. Power Ene. Sys. 33: 594-599.

Kattakayam TA, Srinivasan K (2000) Thermal performance characterization of a photovoltaic driven domestic refrigerator. Int. J. Refrig. 23:190-196.

Li G, Han Y, Li M, Luo X, Xu Y, Wang Y, Zhang Y (2021) Study on matching characteristics of photovoltaic disturbance and refrigeration compressor in solar photovoltaic direct-drive air conditioning system. Re. Energy 172: 1145-1153.

Moffat RJ (1998) Describing the uncertainties in experimental results. Exp Therm Fluid Sci.1:3-1.

Mostafa M, Ezzeldien M, Attalla M, Ghazaly NM, Alrowaili ZA, Hasaneen MF, Shmroukh AN (2021) Comparison of different adsorption pairs based on zeotropic and azeotropic mixture refrigerants for solar adsorption ice maker. Environ Sci Pollut Res (Article in Press). https://doi.org/10.1007/s11356-021-13535-Z

Ndyabawe K, Kisaalita WS (2014) Diffusion of an evaporative cooler innovation among smallholder dairy farmers of Western Uganda. Technol. Soc. 38:1-10.

Opoku R, Anane S, Edwin IA, Adaramola MS, Seidu R (2016) Comparative techno-economic assessment of a converted DC refrigerator and a conventional AC refrigerator both powered by solar PV. Int. J. Refrig. 72:1-11.

Prabakaran R, Lal DM, Devotta S (2021) Effect of Thermostatic Expansion Valve Tuning on the Performance Enhancement and Environmental Impact of a Mobile Air Conditioning System. J Therm Anal Calorim. 143:335-350. 
Rajendran P, Dhasan ML, Narayanaswamy GR (2019) Tuning Thermostatic Expansion Valve for Implementing Suction Line Heat Exchanger in Mobile Air Conditioning System, J Braz Soc Mech Sci Eng. 41:191.

Selvaraj DA, Victor K (2020) Vapour absorption refrigeration system for rural cold storage: a comparative study. Environ Sci Pollut Res (Article in Press). https://doi.org/10.1007/s11356-020-11214-z.

Sharma DK, Sharma D, Ali AHH (2020) A state of the art on solar-powered vapor absorption cooling systems integrated with thermal energy storage. Environ Sci Pollut Res 27: 158-189.

Sidney S, Mohan DL (2016) Exergy analysis of a solar PV driven DC refrigerator for different ambient conditions. IEEE Xplore Digital Library, 280-284.

Sidney S, Prabakaran R, Dhasan ML (2019). Thermal analysis on optimizing the capillary tube length of a milk chiller using DC compressor operated with HFC-134a and environment-friendly HC-600a refrigerants. Proc Inst Mech Eng Part E J Process Mech Eng. 234(4):297-307.

Sidney S, Prabakaran R, Dhasan ML (2021) Charge optimisation of a solar milk chiller with direct current compressors. Proc Inst Mech Eng Part E J Process Mech Eng. 235(3):679-693..

Sidney S, Thomas J, Dhasan ML (2020) A Standalone PV Operated DC Milk Chiller for Indian Climate Zones. Sadhana - Academy Proceedings in Engineering Sciences 45:110.

Torres-Toledo V, Meissner K, Coronas A, Müller J (2015) Performance characterisation of a small milk cooling system with ice storage for PV applications. Int. J. Refrig. 60: 81-91.

Torres-Toledo V, Meissner K, Taschner P, Martınez-Ballester S, Muller J (2016) Design and performance of a small-scale solar ice-maker based on a DC-freezer and an adaptive control unit. Sol. Energy139:433-443.

Xu Y, Ma X, Hassanien RHE, Luo X, Li G, Li, M (2017) Performance analysis of static ice refrigeration air conditioning system driven by household distributed photovoltaic energy system. Sol. Energy 158:147-160. 